\title{
LA OCUPACIÓN DEL DOMINIO PÚBLICO MARÍTIMO-TERRESTRE EN ESPAÑA
}

\author{
Francisco José Torres Alfosea \\ Instituto Universitario de Geografía \\ Universidad de Alicante
}

\section{RESUMEN}

La adecuada gestión del dominio público marítimo terrestre español debe afrontar, en el momento actual, algunos de los problemas más graves de los últimos veinte años. En efecto, dos décadas después de la aprobación de la ley de costas en vigor, el deslinde de las costas en España sigue estando incompleto, la asignación presupuestaria al programa «actuaciones en la costa» es claramente insuficiente (menor, por ejemplo, que el presupuesto de una universidad media), mientras que las concesiones - por definición, ocupaciones temporales del dominio público - tienden a perpetuarse, con prórrogas que responden a motivaciones políticas, y no a una verdadera recuperación de espacios públicos, como demuestra la controversia en 2009 sobre la permanencia o no de los llamados chiringuitos. El informe Auken, por último, ha obligado a replantear la política española, que en los últimos años tendía a una aplicación estricta y rigurosa del articulado legal, causa de numerosos conflictos jurídicos y territoriales. Se contraponen así, ante la opinión pública, ciertas operaciones de demolición de algunas viviendas, frente a la aparente impunidad de grandes inmuebles ubicados en emplazamientos similares. El trabajo que se presenta analiza los diferentes tipos de ocupación en el dominio público, y los problemas que explican la actual dificultad para afrontar su gestión.

Palabras clave: dominio público marítimo-terrestre, ley 22/1988, concesiones administrativas, autorizaciones administrativas, reservas de suelo, adscripciones, informe Auken, deslinde.

\section{ABSTRACT}

A proper management of spanish public shoreline must face at present some of the most serious problems of the twenty past years. Indeed, two decades after the Spanish Coastal Act (passed in 1988), the delimitation of the public appartenances in spanish coasts is still incomplete, the budget allocation to the "Coastal Actions Program» is clearly insufficient (less than, for example, the budget of a medium-sized university), while administrative permissions for temporary occupation of coastal public domain are 
likely to persist, with extensions that politically motivated and not a true restoration of public spaces, as evidenced by the controversy in 2009 over the permanence or otherwise of the chiringuitos (so-called bars).

Auken report finally forced to rethink Spanish politics, which in recent years tended to an strict and rigorous application of legal articles, so that numerous legal disputes and territorial grew.

There is, at least, an apparent contradiction at people eyes between certain strong operations of demolition of some homes, compared with the -apparent- impunity of large property located in similar sites. This paper analyzes the different types of occupation in the coastal public-domain, and the problems that explain the current difficulties facing management.

Key words: maritime public-domain land, spanish coastal law 22/1988, temporary permissions, administrative autorizations, land reserves, assignments, report Auken, demarcation.

\section{Exposición de la situación: usos permitidos en el dominio público marítimo-terrestre en España}

La ley española 22/1988, de Costas (en adelante LC88), contempla la posibilidad de que en el dominio público marítimo-terrestre existan determinados usos privados, y, aunque esto en ningun caso representa cambio de titularidad del suelo, que siempre será pública, es cierto que en la práctica puede determinar situaciones de privatización de facto. Esta afirmación, por grave y rica que pudiera parecer, no refleja sin embargo una verdadera contradicción interna del texto del articulado con el espíritu global de la ley, como se verá.

En este sentido, conviene comenzar indicando que la utilización del dominio público debe ser libre, pública y gratuita (art. 31 LC88) para los usos propios de su naturaleza, tales como el baño, el paseo, la estancia, la varada y botadura de embarcaciones, etc. Esta disponibilidad de usos libre y gratuita se garantiza siempre que no se requieran obras e instalaciones, de manera que no requieren permiso alguno, como por otra parte parece lógico. Incluso en el caso de que requiriesen instalaciones (fijas o no), la cualidad de inembargabilidad que tiene el dominio público marítimo terrestre (recogida ya en el art. 132.2 de la Constitución) impide que exista propiedad privada, en sentido estricto, dentro del dominio público. Esto es contrario a la situación legal anterior, derivada de la primera ley de costas, de 26 de abril de 1969, en la que los bienes de dominio público quedaban definidos sin perjuicio de los derechos legalmente adquiridos, y por tanto, condicionados por ellos. En el ordenamiento jurídico que se establece tras la aprobación de la ley de costas de 1988, podemos decir que determinados usos son libres, mientras otros están específicamente regulados aunque en todo caso la propiedad es siempre pública. No existen, por tanto en España, playas privadas en sentido estricto, ni debe haber limitación alguna al baño o al paseo por el frente costero del Estado.

Tan sólo se permiten instalaciones (sean fijas o desmontables) para aquellos usos y actividades «que, por su naturaleza, no puedan tener otra ubicación» (art. 32.1). En este caso, se tratará de usos bajo un título de ocupación temporal, concedido por la Administración Central, en tanto que última gestora del dominio público marítimo-terrestre. Dichos títulos de ocupación pueden, no obstante, ser otorgados por la Administración local (como sucede muy especialmente en el caso de autorizaciones administrativas para usos de temporada en las playas) y autonómica (determinadas concesiones, por ejemplo la de amarres de uso 
náutico-deportivo), aunque siempre con informe favorable de la Dirección General de Sostenibilidad en la Costa (antes D.G. de Costas) del Ministerio de Medio Ambiente, Rural y Marino, competente en la materia. Tres administraciones por tanto, tienen atribuciones en este campo, recayendo en la ministerial las competencias de aprobación definitiva.

De entre los usos que, por su naturaleza, no puedan tener otra ubicación, destacan los portuarios, los relacionados con el salvamento marítimo (como los puestos de vigilancia y socorro), las instalaciones de evacuación de aguas depuradas y desaladas (emisarios, colectores, salmueroductos...) y similares. No obstante, la normativa española no hace un listado de estas actividades, razón por la cual, en ocasiones, la interpretación puede dar lugar a situaciones invasoras que colisionan con el espíritu del texto. En efecto, se ha esgrimido como necesaria la inmediatez al mar de usos y actividades que, razonablemente, podrían estar emplazadas a mayor distancia de la costa, como puede ser el caso de los clubes de regatas, cuyos locales sociales y dotaciones privativas (piscinas, zonas deportivas, restaurantes...) deberían haberse situado tras la servidumbre de tránsito, en vez de sobre espacios que deberían estar deslindados como zona marítimo terrestre (fig. 1), cuando no en posición palafítica (fig. 2).

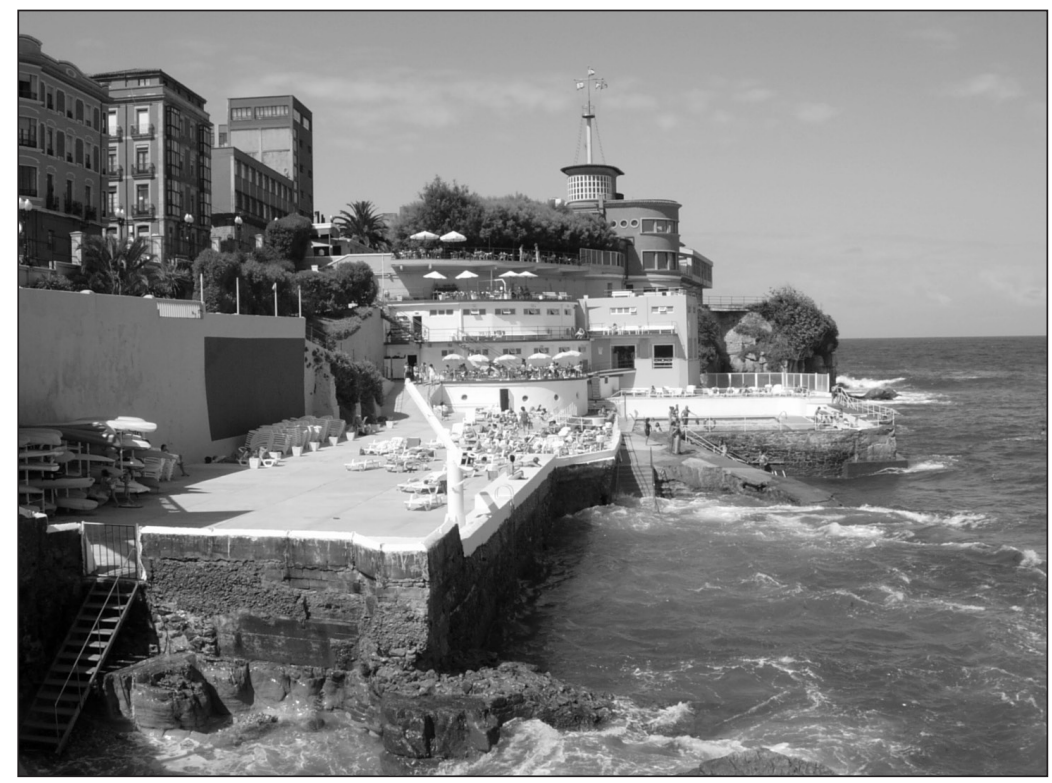

FIgura 1. Real Club Astur de Regatas (Gijón, Asturias).

Foto: Francisco Torres.

Para ocupar con un uso determinado -privado o público- el espacio demanial, es preceptiva la obtención de un título de ocupación. Estos son, en esencia, cuatro: concesiones administrativas, autorizaciones administrativas, reservas de suelo en dominio público y adscripciones. Cada uno de ellos tiene unas características diferentes, y se aplica para actividades distintas, no obstante lo cual comparten el carácter temporal, aunque con diferentes duraciones. 


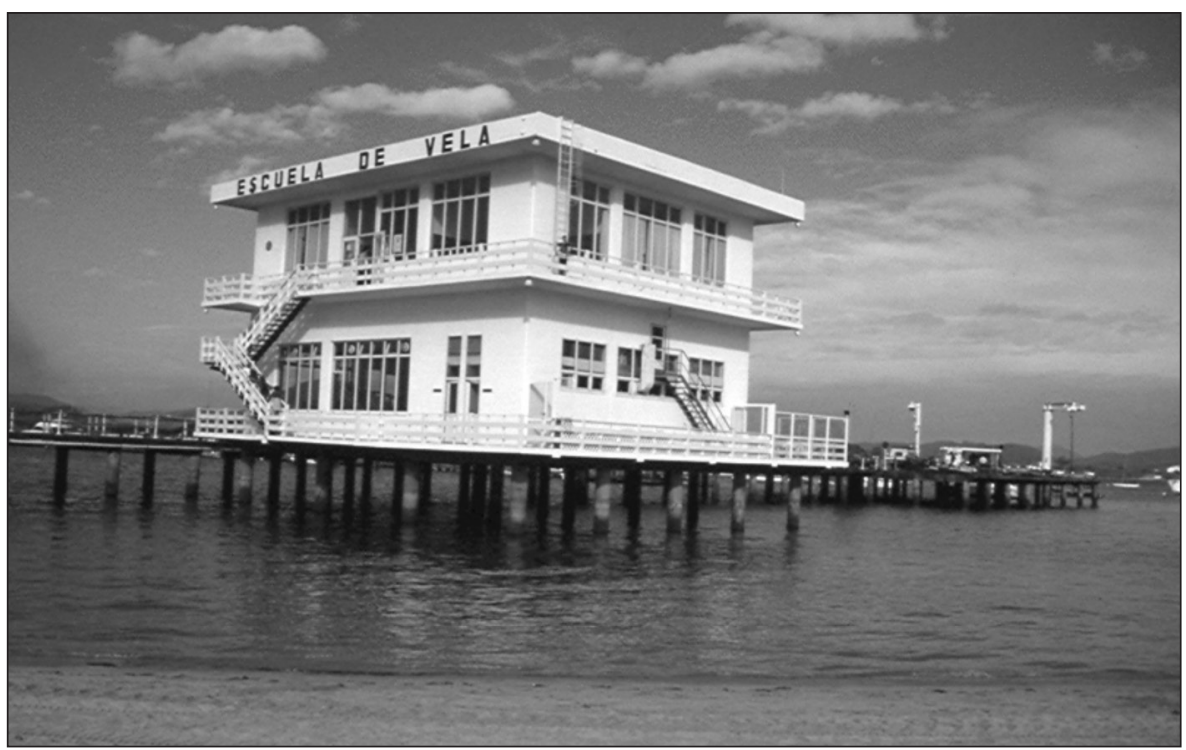

Figura 2. Escuela de vela del Real Club de Regatas de Laredo (Cantabria). Al tratarse de usos relacionados con la naútica se consiente su presencia en este espacio, sin cuestionar que se trate de oficinas y aulas.

Foto: Francisco Torres.

\section{Las ocupaciones ilegales del dominio público}

A la vista de lo anterior, cualquier construcción que no cuente con uno de los cuatro permisos administrativos citados, debe considerarse, de inmediato, como ilegal. Es el caso de las viviendas de autoconstrucción que proliferaron a lo largo de la costa española desde los años 50 del pasado siglo. Cabe interpretarlas como manifestación arquitectónica del veraneo tradicional, permitido en su momento por las autoridades locales y gubernativas, que no veían en estas ocupaciones una amenaza a un ecosistema que, por otra parte, ni siquiera se intuía en peligro, ni, cabe recordarlo, estaba protegido por el ordenamiento jurídico, pues quedaba regulado por la ley de puertos de 1928, que no contemplaba ni las dunas ni la playa seca como parte del espacio demanial.

La entrada en vigor de la ley de Costas en 1988, que responde a un espíritu social y político mucho más sensible al deterioro de estos ambientes anfibios, cambia por completo el panorama. Incorpora numerosos espacios al dominio público, amplía la definición de otros y deja así en una situación de ilegalidad a todas aquellas construcciones que estaban fuera de ordenación, y que serán irremediablemente derribadas en los primeros meses tras la entrada en vigor de la ley, antes incluso de que sea aprobado su Reglamento, en una clara acción demostrativa del poder recuperador que el nuevo texto legal iba a tener en el litoral.

Pero no fueron más que puntuales acciones-demostración. La situación real dista mucho de ser tan sencilla y tan inmediata. Aún hoy en día, veinte años después de la aprobación de la ley, permanecen en pie muchas edificaciones sin título de ocupación, que sólo tras los daños recibidos por un temporal marítimo han sido derribadas por la Administración, previa orden judicial. Valga como ejemplo la siguiente noticia, fechada el 27 de agosto de 2008: 


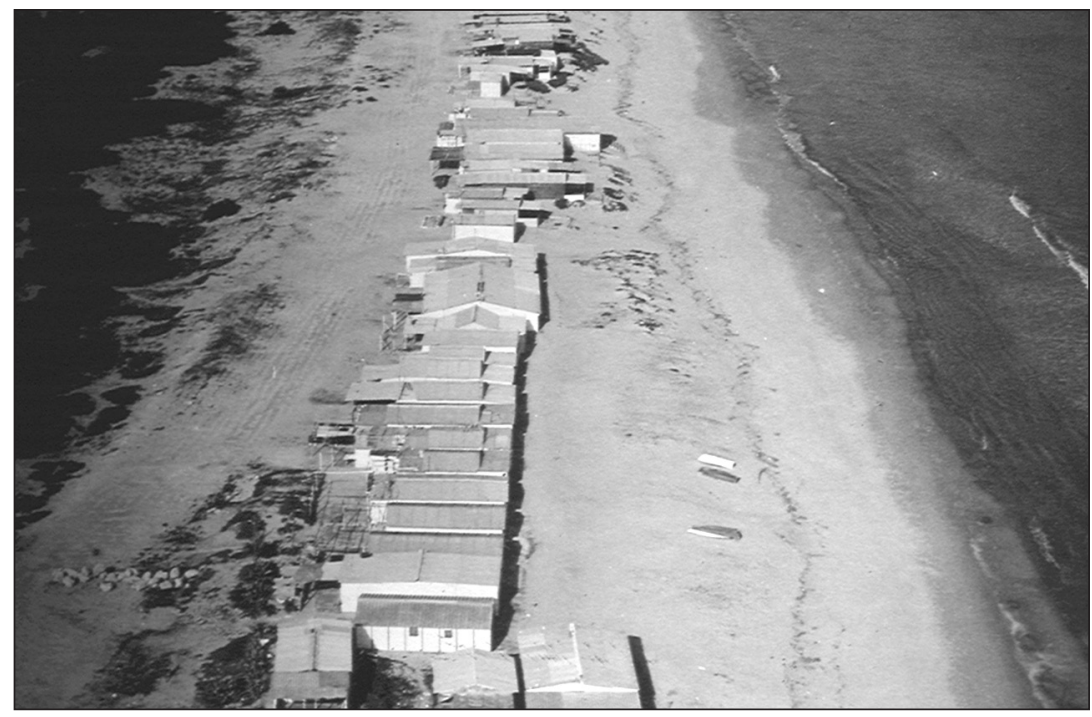

Figura 3. Playa del Rebollo (Guardamar del Segura, Alicante), en abril de 1988. Foto: Archivo de la Dirección General de Costas.

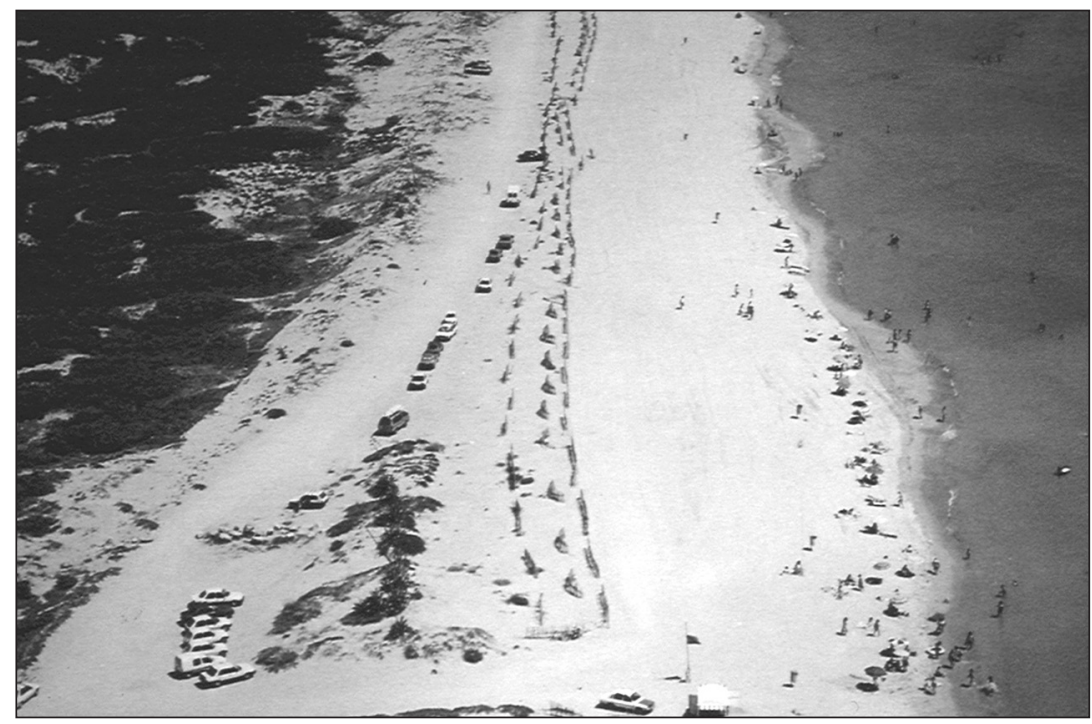

FIgura 4. Playa del Rebollo (Guardamar del Segura, Alicante), en mayo de 1989. Foto: Archivo de la Dirección General de Costas.

Su lectura nos revela que, de las 11 viviendas demolidas en este tramo costero de la provincia de Alicante, nueve carecían de título de ocupación, luego se encontraban en situación de ocupación ilegal; una procedía de una concesión administrativa rescatada 
anticipadamente y otra era propiedad del Estado, de manera que no procedía negociación alguna ni generaba conflicto. La supuesta implacabilidad de la ley, poderosa y expeditiva según la percepción con la que nació, es, por tanto, muy inferior a la que la Administración, con la complicidad de los medios de comunicación, quiere trasladar a la opinión pública.

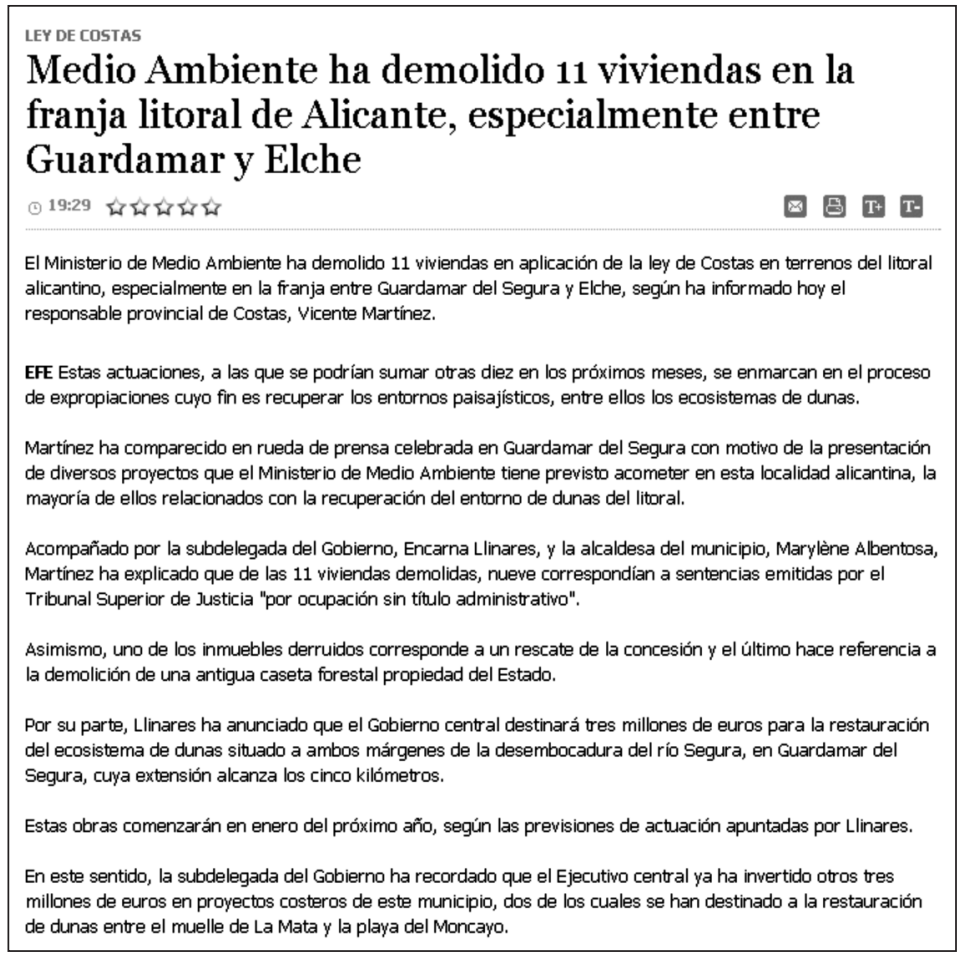

FIgURA 5. Diario Información, 27 de agosto de 2008 (www.diarioinformacion.com)

Este caso no es excepcional. El 7 de octubre de 2008 eran desalojadas del poblado costero de Cho Vito (en la isla canaria de Tenerife), sesenta familias cuyas viviendas se encontraban sobre el dominio público marítimo-terrestre sin título de ocupación. El derribo siguió al desalojo, y los medios de comunicación nacionales se hicieron eco de inmediato de la noticia ${ }^{1}$, remarcando la presencia de otros inmuebles, más altos y más próximos al mar que las viviendas del vecindario demolido, y trasladando así ante la opinión pública una clara sensación de agravio, sin explicar las diferentes condiciones jurídico-administrativas de cada finca, derivadas de la posesión o no de título de ocupación, y, en su caso, de su inclusión o no en el suelo urbano del municipio.

Sin embargo, y a pesar de la gran repercusión mediática y social de estas operaciones de derribo, la Administración suele limitar su acción a la retirada de los escombros, sin acometer verdaderas operaciones de ordenación de la fachada marítima de la zona afectada. Por lo

1 Ver diario El País, de 7 de octubre de 2008. Enlace abreviado: http://tinyurl.com/yklds6f . 
general, al derribo sucede el abandono de la zona, y a esto se añade en muchas ocasiones la afrenta de ver cómo unos centenares de metros más allá, otras construcciones, quizá incluso más elevadas y masivas, permanecen a menos distancia de la orilla por disfrutar del privilegio de estar emplazadas sobre suelo urbano o bien por contar con un título de ocupación, aunque fuera temporal.

Resulta, a priori, contradictorio con la norma afirmar que los particulares (y por tanto aparentemente la propiedad privada) pueden estar presentes en el dominio público. En ningún caso, sin embargo, esto representa un cambio de titularidad del suelo, que sigue siendo público, aunque se autorizan, y a veces por periodos dilatados de tiempo, determinados usos privados, incluso lucrativos y residenciales, en el dominio público marítimo-terrestre. Desarrollemos esto:

\section{La legalidad de una construcción no depende de la distancia a la costa}

La ley de costas española, al igual que otros textos similares, establece unos umbrales métricos a partir de los cuales puede comenzar el dominio privado. En el imaginario colectivo permanece la idea de que los cien primeros metros a contar desde la línea de costa pertenecen al dominio público, y por tanto en ellos no puede haber ninguna construcción, ni mucho menos propiedad privada. Este centenar de metros proviene de la amplitud teórica que alcanza la servidumbre de protección, que la población interpreta, erróneamente, como un lugar que debe quedar desprovisto de edificación. La realidad es que esto no es así. La ley de Costas distingue y define los bienes de dominio público (recursos de la ZEE y la plataforma continental, mar territorial, zona marítimo terrestre, playas, dunas, acantilados, accesiones al mar...). Procede, pues, en primer lugar, ubicarlos en cada tramo costero y separarlos del espacio interior mediante el deslinde. Tras la línea de deslinde, comienzan a contar las servidumbres, una de las cuales, la citada servidumbre de protección, sólo alcanza los 100 metros (eventualmente ampliables cien más) en el caso de que se extienda sobre suelo clasificado como no urbanizable (o bien urbanizables «no programados», según la antigua denominación) en el documento de planeamiento que rija en el municipio.

La servidumbre de protección no impide, por otro lado, la presencia de propiedad privada en ella, dado que los límites que impone la ley de Costas aluden a los usos posibles, y no a la propiedad. Así, el artículo 25 enumera las actividades prohibidas en este espacio, entre las que aparecen, en primer lugar «las edificaciones destinadas a residencia o habitación» ${ }^{2}$. No es posible, pues, la construcción de espacio residencial en esos primeros cien metros contados a partir de la línea de deslinde, aunque no hay problema alguno en que, en esa zona, se ubiquen las piscinas, pistas de tenis, espacios lúdico-recreativos o incluso edificaciones para uso comercial y de restauración. El carácter protector de la servidumbre de protección queda, así, en entredicho, precisamente en aquellos lugares donde ésta podía ser máxima, alcanzando el centenar de metros, y que son aquellos en los que el suelo estaba clasificado como no urbanizable o urbanizable no programado (categoría ya extinta) a la entrada en vigor de la ley de Costas. Así sucede en la figura 6, en la que los edificios de apartamentos de la derecha de la imagen están precedidos por los jardines, piscinas, fuentes y demás espacios artificiales construidos ante ellos; por tanto, dentro de una propiedad privada establecida en servidumbre de protección, mientras que el uso residencial no se localiza hasta pasado el centenar de metros.

2 Art. 25.1. de la LC88. Se entiende por uso de habitación el hotelero. 


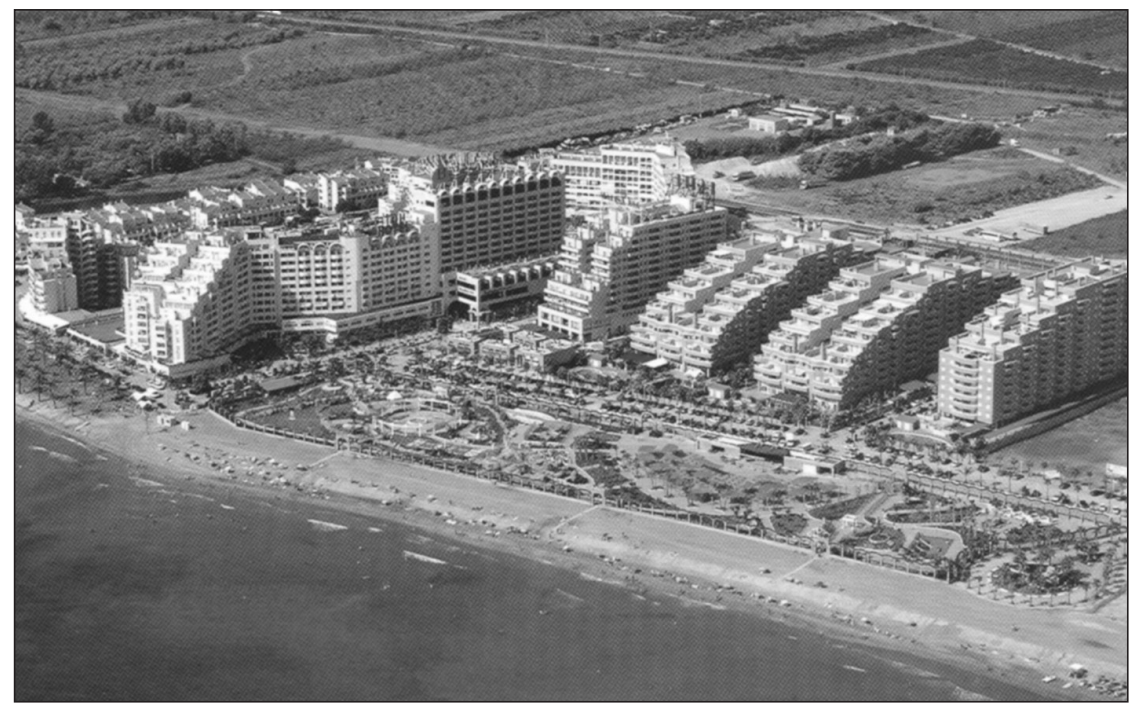

FIgura 6. Marina d'Or, Oropesa (Castellón).

Por el contrario, en los terrenos que, a la entrada en vigor de la ley estuvieran clasificados como urbanos, la servidumbre de protección queda reducida en un $80 \%$, limitada por tanto a 20 metros, que son herencia de la antigua servidumbre de vigilancia establecida por la extinta ley de aguas de 1866 . Y esa veintena de metros puede incluso desaparecer si atendemos a la frase remarcada en el párrafo siguiente, que corresponde a la Disposición Transitoria novena del Reglamento de la ley de Costas:

«Novena. 1. Los terrenos clasificados como suelo urbano a la entrada en vigor de la Ley de Costas, estarán sujetos a las servidumbres establecidas en ella, con la salvedad de que la anchura de la servidumbre de protección será de veinte metros. No obstante, se respetarán los usos y construcciones existentes, así como las autorizaciones ya otorgadas, en los términos previstos en la disposición transitoria cuarta de la Ley de Costas y concordantes de este Reglamento»3.

No cabe, pues, perjuicio a las construcciones existentes, ni siquiera aunque la distancia a la costa sea reducida y claramente inferior a los cien o incluso a los veinte metros estipulados. Es determinante, así, el tipo del suelo sobre el que se asiente la actividad. Los suelos clasificados como urbanos se mantienen en un teórico aparte de las determinaciones de las servidumbres, mientras que éstas alcanzan su máxima aplicabilidad en los no urbanizables. Los suelos urbanizables, por su parte, se encuentran en una situación intermedia: deben atender las determinaciones de la ley - especialmente en lo que respecta al cómputo y medición de las servidumbres - si aún no cuentan con plan parcial aprobado, mientras que, si éste ya lo está, el suelo, a todos los efectos, debe considerarse como urbano, y por tanto teóricamente ajeno a las disposiciones más restrictivas.

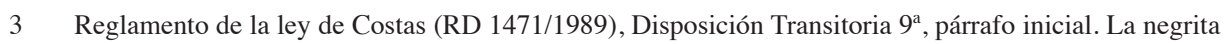
es nuestra. 
Y decimos teóricamente, porque en la práctica nada impide que, tras un replanteamiento del deslinde, edificios inicialmente situados sobre suelo clasificado como urbano, ocupen el dominio público marítimo terrestre. Esto puede ocurrir muy especialmente cuando no se ha materializado una servidumbre de tránsito tras el dominio público, es decir, cuando no se cuenta con un paseo marítimo ante las viviendas, que es, siempre, la principal exigencia de los ocupantes de las primeras líneas, puesto que, en virtud de lo dispuesto en los arts. 27 y 44.5 la presencia del paseo ratifica su posición fuera del demanio, y por tanto, dentro del dominio privado. En otras ocasiones, en las que el paseo marítimo está ausente y las edificaciones ocupan un espacio que pudiera eventualmente verse afectado por el oleaje en los mayores temporales conocidos, el deslinde practicado podría incorporarlas a la zona marítimo terrestre, por tanto al dominio público, excepto en el caso de que se trate de suelos clasificados como urbanos antes de la entrada en vigor del texto legal 22/1988.

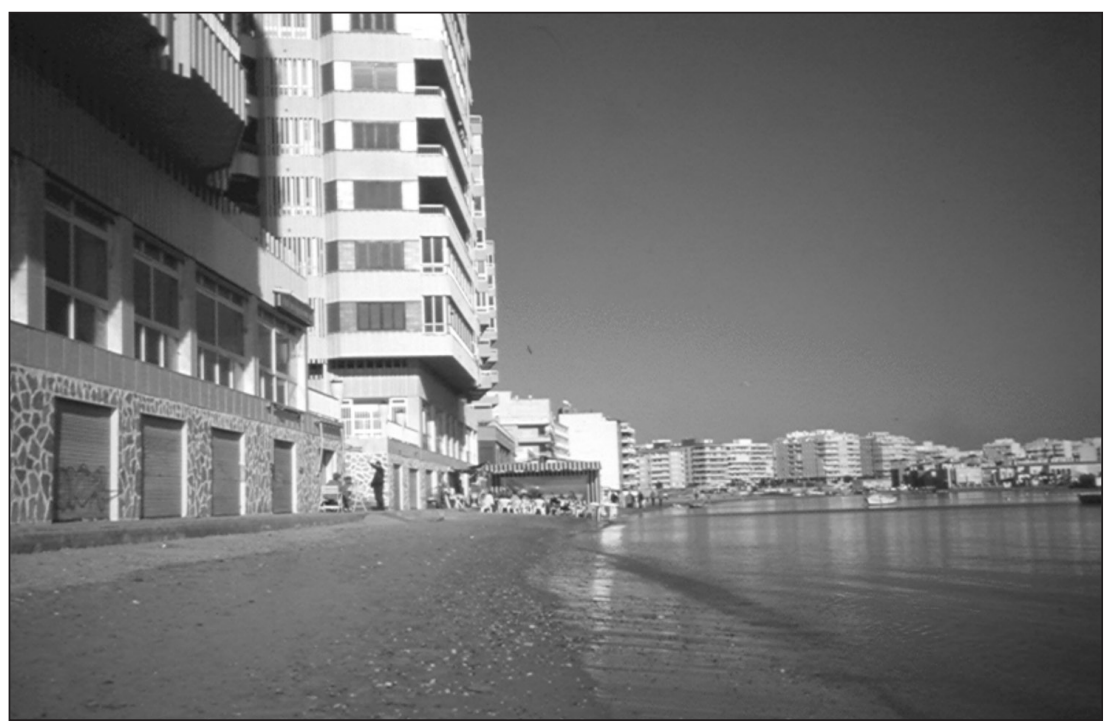

Figura 7. Playa del Acequión (Torrevieja, Alicante).

Foto: Francisco Torres.

Atender a la clasificación del suelo, es pues, clave para comprender la legalidad de situaciones como las de la figura 7, cuya cercanía al mar, sin embargo, no transgrede lo dispuesto en la ley, por tratarse de suelo urbano. Se puede entender, no obstante, con facilidad, el aparente agravio que se produce entre el tratamiento otorgado a unas u otras edificaciones en función del tipo de suelo sobre el que se asientan, y no en virtud de su cercanía o no al mar que es, razonablemente, lo que la ciudadanía podría esperar de la aplicación de una ley que hacía gala, en su Exposición de Motivos, de una decidida voluntad de recuperación de la costa para uso público. Reacciones ciudadanas como las producidas en Cho Vito (Tenerife) en octubre de 2008 son, en ese caso, perfectamente comprensibles. 


\section{Ocupación legal del dominio público marítimo-terrrestre por particulares: los títulos de concesión y los conflictos derivados}

Las ocupaciones particulares del dominio público legalizadas antes de la entrada en vigor de la Ley, devienen en concesiones administrativas

La intensa urbanización de la costa española desde principios de los años sesenta genera un escenario extraordinariamente conflictivo en el momento de la entrada en vigor de la ley. Numerosos edificios se encontraban en terrenos que, con el nuevo texto, deberían ser considerados dominio público (por ejemplo, la parte posterior de la playa, o entre los cordones dunares, hasta entonces aún no incorporados al demanio). Y administrativamente, sin embargo, contaban con todos los permisos (licencias de obras, cédulas de habitabilidad, inscripción en el registro de la propiedad), puesto que se trataba de edificios amparados en su momento por la legislación en vigor (habitualmente la ley de costas de 1969 o subsidiariamente la de puertos de 1928).

Para evitar el perjuicio a los ocupantes derivado de la entrada en vigor del nuevo texto, el legislador pudo optar por dos soluciones: o bien la indemnización económica o bien la conversión de los propietarios en titulares de un derecho de ocupación temporal. La primera opción, en caso de haber sido justa, muy probablemente habría sido la elegida por los propietarios, aunque extraordinariamente gravosa para las arcas públicas, y de gran complejidad por la dificultad de hallar un justiprecio razonable y consensuado con los propietarios de las primeras líneas lo que obligaría a negociaciones en conjunto y no individualmente, que habrían elevado el precio de las últimas viviendas en ser adquiridas por la Administración. La segunda opción, menos costosa económicamente y en principio menos compleja, fue la escogida, a pesar de que de ella se derivaba una extraordinaria complicación jurídica. La Transitoria Primera del Reglamento de la ley de Costas recoge esta opción finalmente adoptada:

«1. En virtud de lo dispuesto en el artículo 132.2. de la Constitución, los titulares de espacios de la zona marítimo-terrestre, playa y mar territorial que hubieran sido declarados de propiedad particular por sentencia judicial firme anterior a la entrada en vigor de la presente Ley pasarán a ser titulares de un derecho de ocupación y aprovechamiento del dominio público marítimo-terrestre a cuyo efecto deberán solicitar la correspondiente concesión en el plazo de un año a contar desde la mencionada fecha. La concesion se otorgará por treinta años, prorrogables otros treinta, respetando los usos y aprovechamientos existentes, sin obligación de abonar canon, y se inscribirá en el Registro a que se refiere el artículo $37.3 »^{4}$.

Por tanto, los - hasta entonces - propietarios de viviendas en terrenos que resulten incorporados al dominio público, deberían solicitar en el plazo de un año la conversión en concesionarios por un periodo de treinta años (prorrogables otros treinta en el caso de contar con inscripción registral). La solución, por tanto, queriendo ser equitativa, en la práctica colocaba en desamparo a los propietarios, que no sólo dejaban de serlo (con lo que esto implica económicamente), sino que además veían muy limitada su capacidad de actuar en sus viviendas, en tanto que cualquier obra de mejora (incluso de tipo menor, como el pintado de la fachada, o el cambio de la carpintería exterior) debía contar con el 
preceptivo permiso de la (entonces llamada) Dirección General de Costas, por tratarse de obras a ejecutar en zona marítimo-terrestre o playas. No es de extrañar que una medida de este tipo se entendiera como una amenaza a la propiedad privada, tal y como se recogía en la prensa de la época (fig. 8):

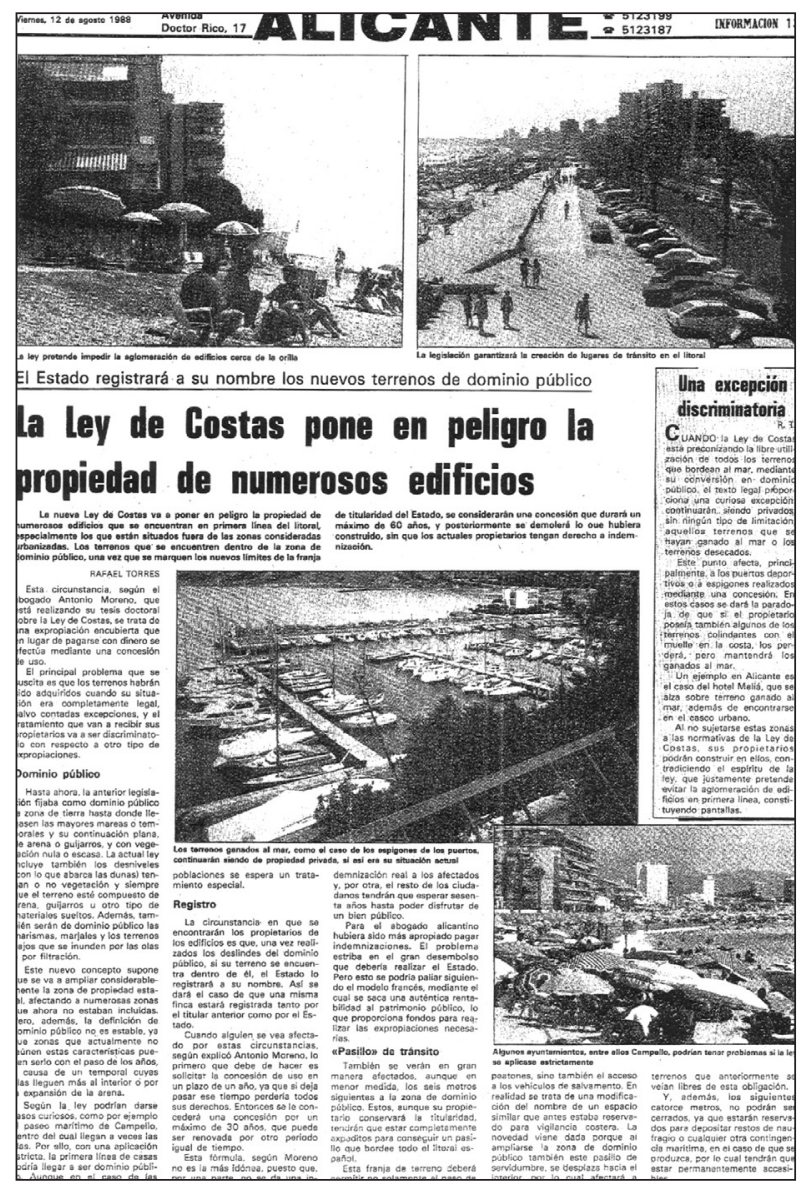

FIGURA 8. Diario Información, del 12 de agosto de 1988.

La solución, como puede imaginarse, no fue del agrado de la ciudadanía afectada, que se veía víctima de un cambio legislativo, mientras que la Administración anterior, que autorizó sin problemas dichas construcciones, no respondía de modo alguno en este proceso. Los recursos de los propietarios no tardaron en llegar, y lo que en principio iba a ser un procedimiento más o menos ágil, acabó convirtiéndose en un asunto de extraordinaria complejidad jurídica: la mayor parte de las situaciones de conversión en concesiones administrativas acabó en los tribunales, en dilatados procesos que, en el mejor de los casos, han tardado entre diez y quince años en solucionarse, y en otros, la mayoría, aún están pendientes de resolución por parte del Tribunal Supremo, una vez agotadas las vías previas de tramitación. 


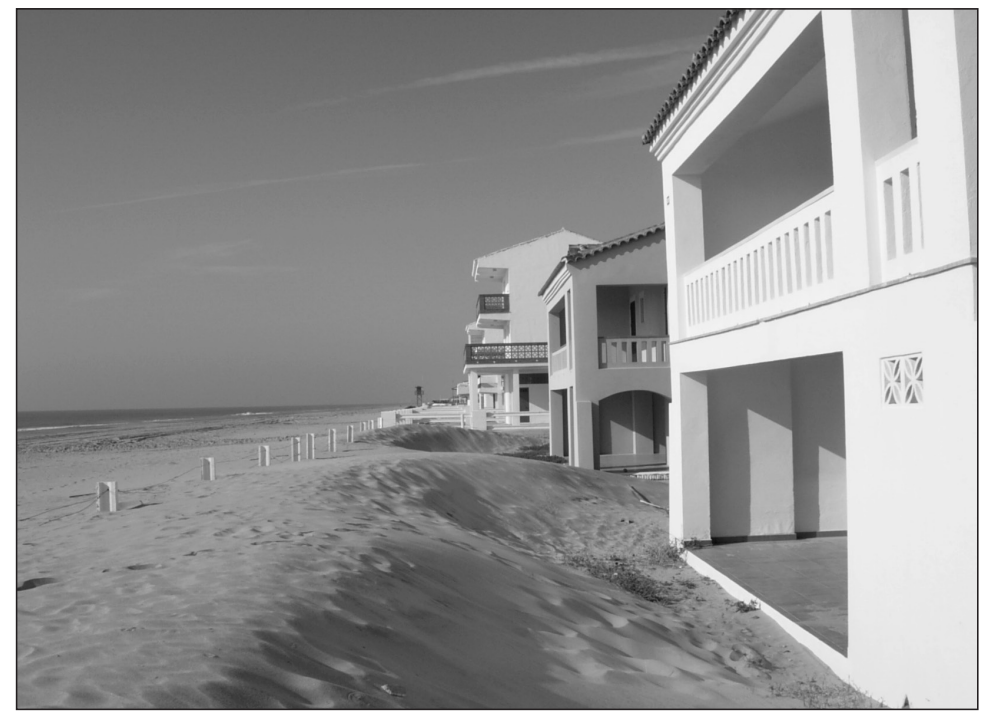

FIgURA 9. Playa de Islantilla (Huelva).

Foto: Francisco Torres

\section{Características de las concesiones administrativas}

De este modo, el título de concesiones administrativas, que inicialmente estaba reservado para usos lucrativos en el litoral de larga duración (puertos deportivos, por ejemplo), acaba siendo aplicable también para los usos residenciales, si bien a resultas de la entrada en vigor de la ley y fruto de una transitoria pensada para minimizar el perjuicio a los propietarios. Las características de estos títulos de ocupación son las siguientes:

- Pueden acoger tanto a usos lucrativos (negocios como restaurantes, tiendas de souvenirs, etc.) como a usos residenciales, aunque en este último caso sea, como se ha visto, por la aplicación en determinados casos, de la Transitoria Primera.

- Son otorgadas directamente por la Administración central (en el caso de concesiones para usos residenciales), o bien - aunque subsidiariamente - por la Autonómica (en el caso de amarres para uso náutico-deportivo) tras la preceptiva adscripción de suelo, como veremos.

- Las concesiones administrativas se otorgan por un periodo de tiempo amplio: de varios años (generalmente entre cinco y diez) en el caso de usos lucrativos, aunque pueden llegar a los mencionados 30+30 en el caso de los usos residenciales.

- Durante el periodo que dure la concesión, el titular (ex-propietario en el caso de los usos residenciales) no puede emprender obras en su negocio o vivienda sin el permiso de la Administración (actualmente estas atribuciones corresponden a la Dirección General de Sostenibilidad en la Costa, dependiente del Ministerio de Medio Ambiente y Medio Rural y Marino).

- Las concesiones no son transmisibles intervivos, es decir, no pueden venderse. Tan sólo en caso de fallecimiento del titular, sus causahabientes pueden heredarla (en los términos fijados por el otorgamiento del título, y por el tiempo que reste de 
concesión), aunque para ello deben reclamar la transmisión en el plazo de un año tras el fallecimiento (art. 70 LC88). Sólo si la concesión lo es de un servicio que se preste al público (restaurantes, por ejemplo), cabe la transmisión, aunque con ciertas limitaciones, contando con la preceptiva autorización y sólo por el tiempo de concesión restante.

- Puede tratarse de inmuebles de obra, es decir, no desmontables fácilmente.

- Cuando la concesión caduca, existen dos posibilidades:

a) Si se trataba de concesión para uso residencial, se considera extinguido el derecho de ocupación, y la construcción debe ser retirada, para devolver el lugar a las condiciones anteriores a su construcción. Siempre y cuando, claro, haya sentencia firme en este sentido.

b) Si, por el contrario, se trataba de una concesión para el desempeño de una actividad lucrativa en el dominio público, la Administración tiene la potestad de sacarla de nuevo a concurso, en las condiciones que estime oportunas, de acuerdo con el marco legal.

- Puede darse el caso, no infrecuente dada la ubicación de estas actividades, de que los temporales dañen gravemente las estructuras construidas. Si el técnico competente (arquitecto municipal por lo general) elabora una declaración de ruina para garantizar la seguridad de los ocupantes y transeúntes, estas concesiones son demolidas anticipadamente, y los titulares indemnizados aunque sólo por el uso no disfrutado de la concesión pendiente. Así sucedió en las casas de Babilonia, concesiones administrativas en el término municipal de Guardamar del Segura (Alicante), afectadas por un fuerte temporal de levante en enero de 2008 (fig. 10).

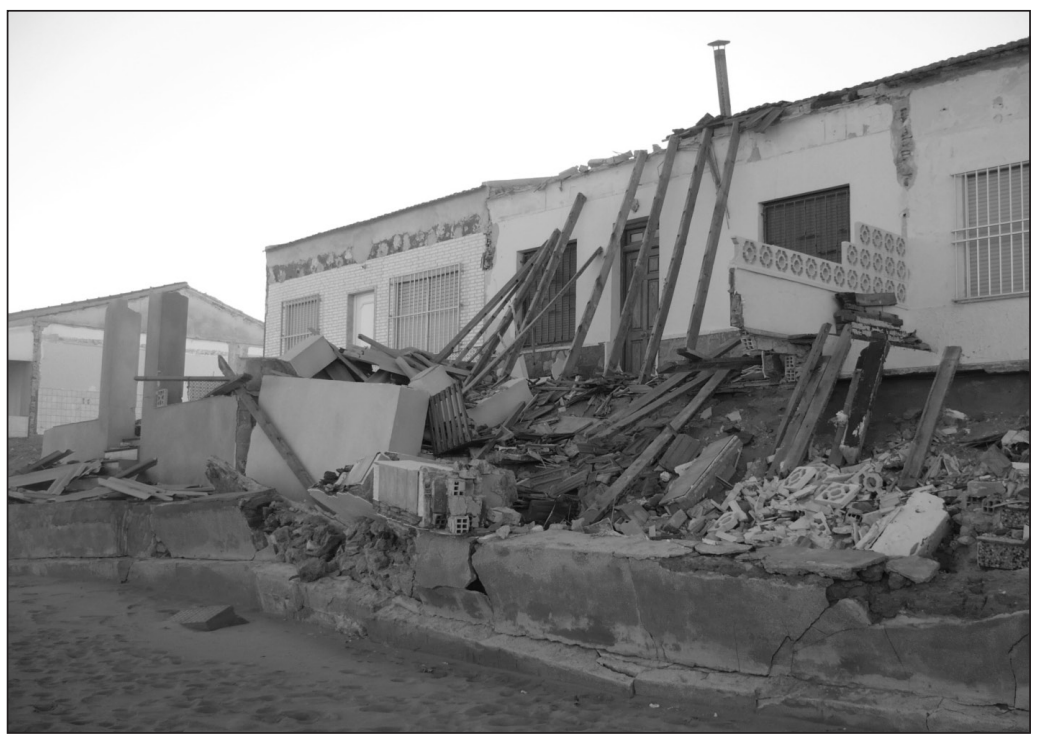

Figura 10. Concesiones administrativas sobre la Playa de Babilonia (Guardamar del Segura, Alicante), tras el temporal de 16 de enero de 2008. Varias de ellas fueron demolidas anticipadamente tras ser declaradas en ruina, aunque la concesión preveía su presencia hasta 2018. Foto: Francisco Torres. 


\section{Estudio de caso 1: Ocupación residencial de temporada en el dominio público (playa El Pinet. Elche, Alicante)}

El 17 de febrero de 1948 se autorizó la construcción de algunas viviendas en la primera línea de la Playa de El Pinet (Elche), entre el cordón dunar (a su espalda) y una playa que ofrecía en ese momento una anchura de unos cincuenta metros. La normativa en vigor - ley de Puertos de 1928 - consentía dicha ocupación, en la medida en que las dunas no formaban parte del dominio público, ni tampoco la playa seca, es decir, la que quedaba fuera del influjo de las olas en los mayores temporales ordinarios ${ }^{5}$.

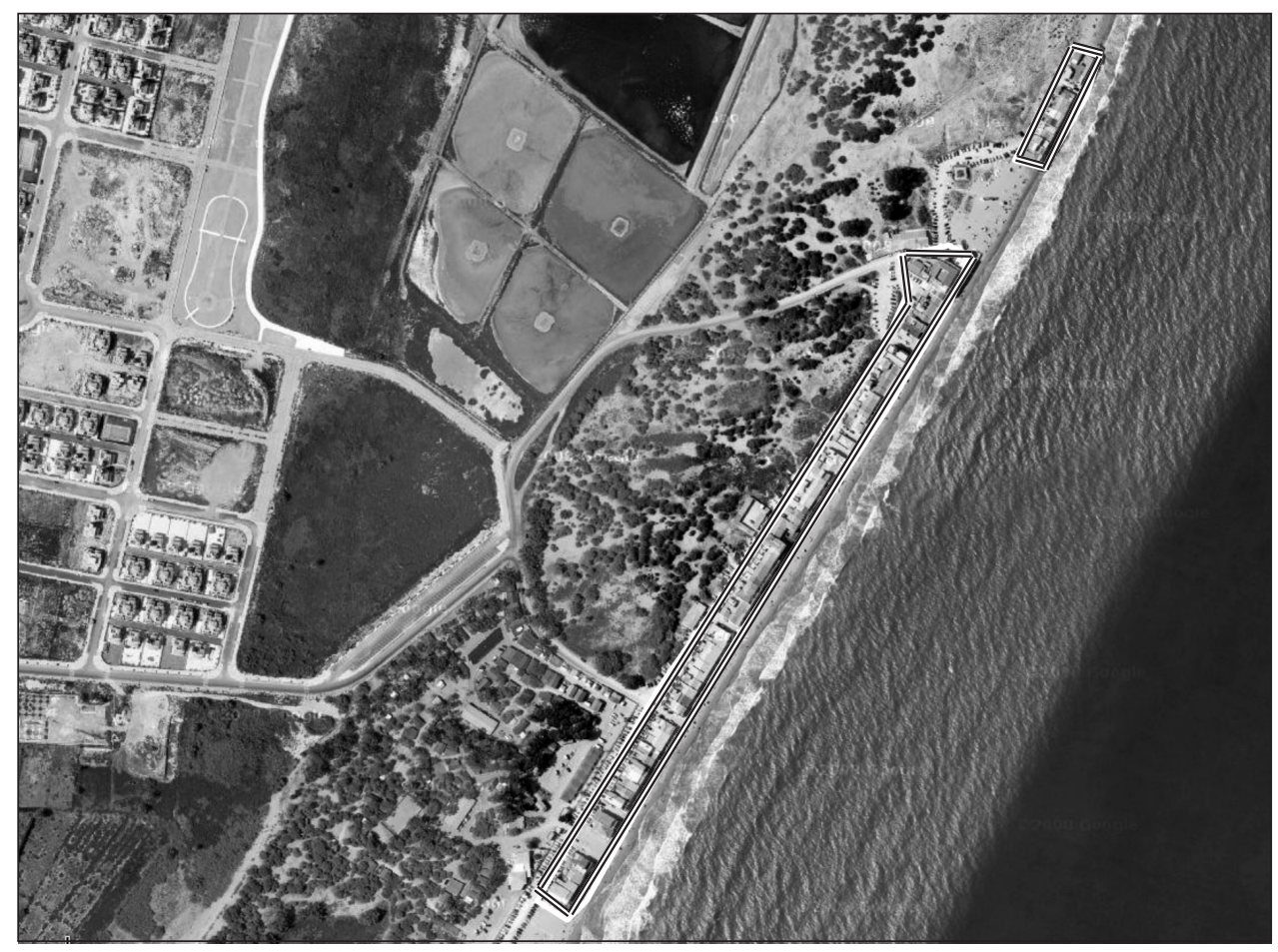

Figura 11. Playa de El Pinet (La Marina, Elche. Provincia de Alicante).

Imagen: www.maps.google.com. Se han marcado las viviendas que son objeto de este estudio.

Se va constituyendo de este modo un espacio de veraneo tradicional, en viviendas unifamiliares adosadas donde se cohesiona una comunidad que alcanzará en torno al centenar de vecinos, la mayor parte de ellos procedentes del municipio próximo - pero de interior - de Crevillente. Al cabo de diez años, se produce el primer conflicto entre uno de los propietarios y la Administración, cuando en 1958 uno de los vecinos solicitó permiso

5 La expresión olas en los mayores temporales ordinarios, a pesar de su incongruencia semántica, se ha mantenido en vigor en España durante más de cien años, desde la Ley de puertos de 1880 hasta la entrada en vigor de la Ley de Costas de 1988. El lugar alcanzado por ellas marcaba el límite interior de la zona marítimoterrestre, primero de los bienes de dominio público emergidos. 
para ampliar su vivienda, que fue denegado por el Servicio de Costas, lo que invalidaba la obra, pues en virtud del artículo 38 de la ley de Puertos de 1928, «En ningún punto de las costas, playas, puertos y de los ríos ni en las islas formadas en la zona marítima, se podrán ejecutar obras nuevas, de cualquier especie que fueren, ni construirse edificio alguno sin la competente autorización».

En 1962, sin embargo, el Ayuntamiento de Elche interviene como actor en el proceso, al aprobar el Plan Especial de Ordenación de La Marina. En él se indica que «Las barracas o instalaciones de temporada que tradicionalmente se han venido concediendo para ser levantadas en primera línea de playa, se considerarán a extinguir en el futuro, si bien, y en atención al nivel económico y social de sus usuarios y al hecho de haber formado una comunidad estacional de convivencia durante largos años estabilizada y con fuertes vínculos de relación social, se podría permitir que siguiesen levantándose al otro lado de la carretera, al pie de la pinada, sin privatizar el acceso a la playa ni cortarla de vistas desde el futuro paseo marítimo. En todo caso, no se otorgarán concesiones de este tipo y para este uso a usuarios nuevos, manteniéndose estrictamente los que en años precedentes la hubieran obtenido».

El argumento es complejo, y poco afortunado: se consideran a extinguir, y sin embargo se consienten, aludiendo a razones de tipo subjetivo, como los vínculos sociales existentes entre los vecinos. Por otra parte, se permite la construcción de nuevas casas, pero detrás de la carretera (pese a todo, entre las dunas y la playa), pero sólo a los titulares de concesiones, aun cuando esta competencia escapa al Ayuntamiento y, desde luego, podría ser motivo de recurso ante los tribunales. Por último, se anuncia un futuro paseo marítimo - que garantizaría definitivamente la permanencia de estas viviendas, por constituir la materialización de la servidumbre de tránsito, y por tanto marcaría el fin del dominio público - lo que sería incompatible con la primera frase, que declaraba la intención de considerarlas a extinguir en el futuro. La sucesión de desatinos en este Plan fue convenientemente aprovechada por los vecinos, que aludieron a él constantemente durante los recursos que presentaron en los años siguientes contra la Administración Central, para reforzar sus planteamientos.

En 1969 se aprueba la primera ley de Costas española que preserva y garantiza en su primer artículo los derechos legítimamente adquiridos de los propietarios de viviendas situados en el dominio público, y da prioridad, por tanto, a la propiedad privada en espacios demaniales. Dos años más tarde, en 1971, y amparándose en lo anterior, otro vecino solicita permiso para legalizar su chalet, con el fin de proceder a su venta. Obtiene el permiso favorable del Ministerio de la Vivienda, pero la negativa de la Jefatura de Costas. Los recursos presentados por el propietario - primero- y Costas después, se resuelven en la Audiencia Nacional (1973) y el Tribunal Supremo (1975), fallando ambos a favor del propietario, y reconociendo la legalidad de las viviendas.

En 1982, de nuevo el ayuntamiento de Elche las incorpora en un documento de ordenación, incluyéndolas en el Catálogo de edificios protegibles, atendiendo a «su tipismo y características urbanísticas», lo que — otra vez - permite a los vecinos albergar esperanzas para que, en el futuro, se construya el paseo marítimo del que se hacía mención en 1962.

La playa va reduciendo su anchura progresivamente a lo largo de los años ochenta, en los que ya ofrece menos de una veintena de metros. Sin duda, las obras de regeneración en las playas próximas (con espigones que interrumpen la dinámica litoral en Playa Lissa y Gran Playa) y las obras de encauzamiento del río Segura son también causas de esta acelerada regresión, y no sólo la presencia de las viviendas, interpuestas entre playa y dunas, y que llevaban emplazadas en la zona desde hacía treinta años, durante los cuales el perfil de la playa había manifestado mucha mayor estabilidad que en los últimos diez. 
En 1988, en fin, con la entrada en vigor de la segunda - y actual - ley de Costas, se produce un cambio sustancial en la situación. Una de sus principales novedades es que considera las dunas dentro del dominio público, y como en el caso que nos ocupa se encuentran tras las viviendas, deja a éstas dentro del espacio demanial; como tales, deben ser convertidas en concesiones administrativas, especialmente si tenemos en cuenta que el Plan General de Ordenación Urbana de Elche nunca las incorporó al suelo urbano. La conversión en concesión, sin embargo no es automática; debe producirse tras acuerdo o sentencia judicial. Sin embargo, la administración Central, a través del Ministerio de Obras Públicas, no lo entendió así. En efecto, en 1994 el entonces Ministerio de Obras Públicas, Transportes y Medio Ambiente publicó en el Boletín Oficial de la Provincia el Proyecto de Ordenación, Regeneración y Defensa de las Playas de El Pinet y Las Pesqueras. En dicho proyecto se prevé, de manera urgente y prioritaria, el derribo de las casas y la posterior retirada de los escombros, aunque no anuncia más actuaciones. La anchura de la playa estaba ya en torno a tan sólo cinco metros. Se descarta, por su elevado coste, el aporte artificial de arena.

El argumento de la Administración para el derribo se basa en la pretendida extinción de las concesiones: si las viviendas se construyeron en 1948 (y años siguientes), y la ley de Costas de 1988 las convierte en concesiones por un periodo de treinta años, éstas deben entenderse caducadas. Sin embargo, puesto que esa decisión corresponde a un tribunal, no a un Ministerio, y dado que a lo largo de los decenios anteriores hubo sentencias que les fueron favorables, los vecinos se movilizan de inmediato, y reclaman la suspensión del proyecto. Una asociación nacional de afectados por situaciones similares entra en escena, y facilita apoyo jurídico a los vecinos. Entre todos ellos (poco más de un centenar de familias) presentan 4.600 alegaciones al proyecto. La tramitación exige que la Administración responda individualmente y de forma razonada a cada una de estas alegaciones, lo que paraliza el procedimiento temporalmente y da tiempo a los vecinos. Exactamente seis meses.

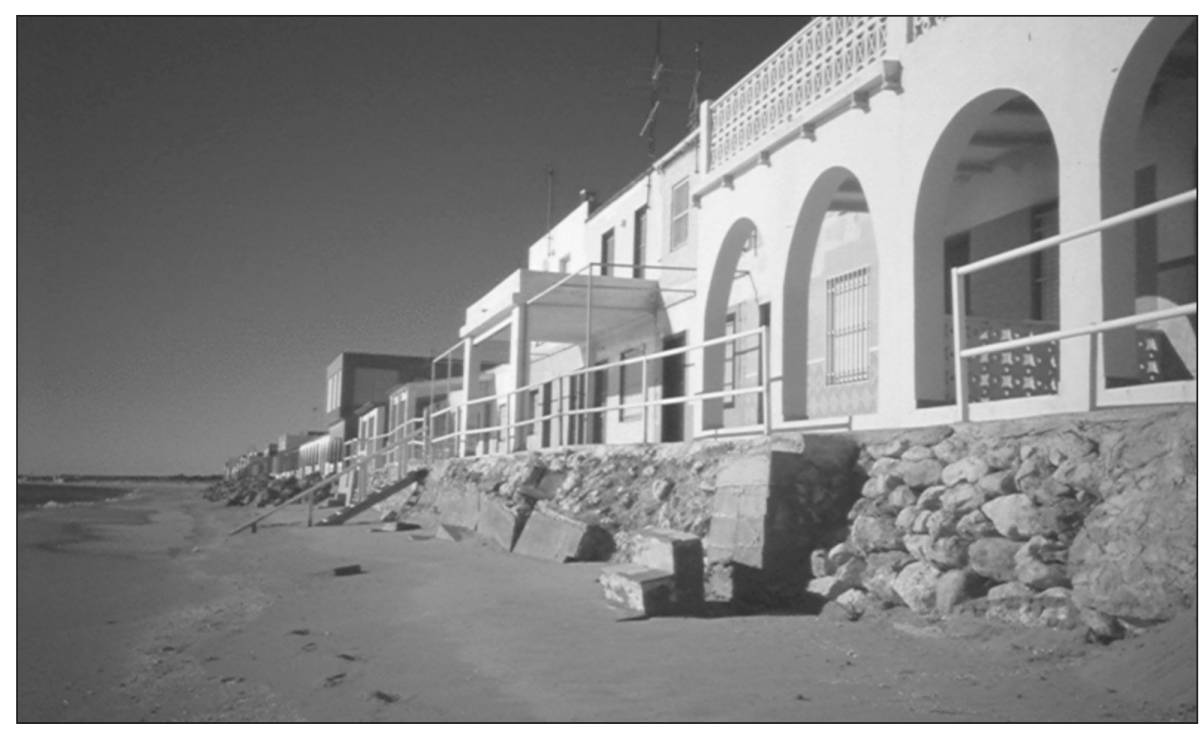

Figura 12. Viviendas en régimen de concesión administrativa. Playa del Pinet (Elche, Alicante).

Foto: Francisco Torres. 
Tramitadas las alegaciones, son todas denegadas, excepto una, presentada por el gobierno autonómico, que sugería la conveniencia de redactar un Plan Integrado del Litoral, de manera que el proyecto de regeneración no quedara limitado tan sólo al derribo de las viviendas. Mientras tanto, varios temporales de levante afectan gravemente a las construcciones, por lo que los vecinos deciden emprender obras de mejora y refuerzo de sus viviendas, que incluyen la construcción de un dique-escollera delante de las casas. Son sancionados por invasión del dominio público marítimo terrestre. Llegan, incluso, a presentar querellas criminales contra los responsables provincial y nacional de la Jefatura de Costas, que son desestimadas. Por fin, el 10 de septiembre de 1996, la Audiencia Nacional falla una resolución equilibrada: las viviendas deben entrar, efectivamente, en régimen de concesión, atendiendo a lo dispuesto en la Transitoria Primera de la ley de Costas, pero el inicio de la concesión no debe ser la fecha de su construcción, sino la de la entrada en vigor de la Ley; es decir, 1988, lo que permite la existencia de las viviendas hasta 2018, al menos mientras los temporales de levante las respeten.

\section{Estudio de caso 2: Ocupación residencial de carácter principal en el dominio público (Albufereta, Alicante)}

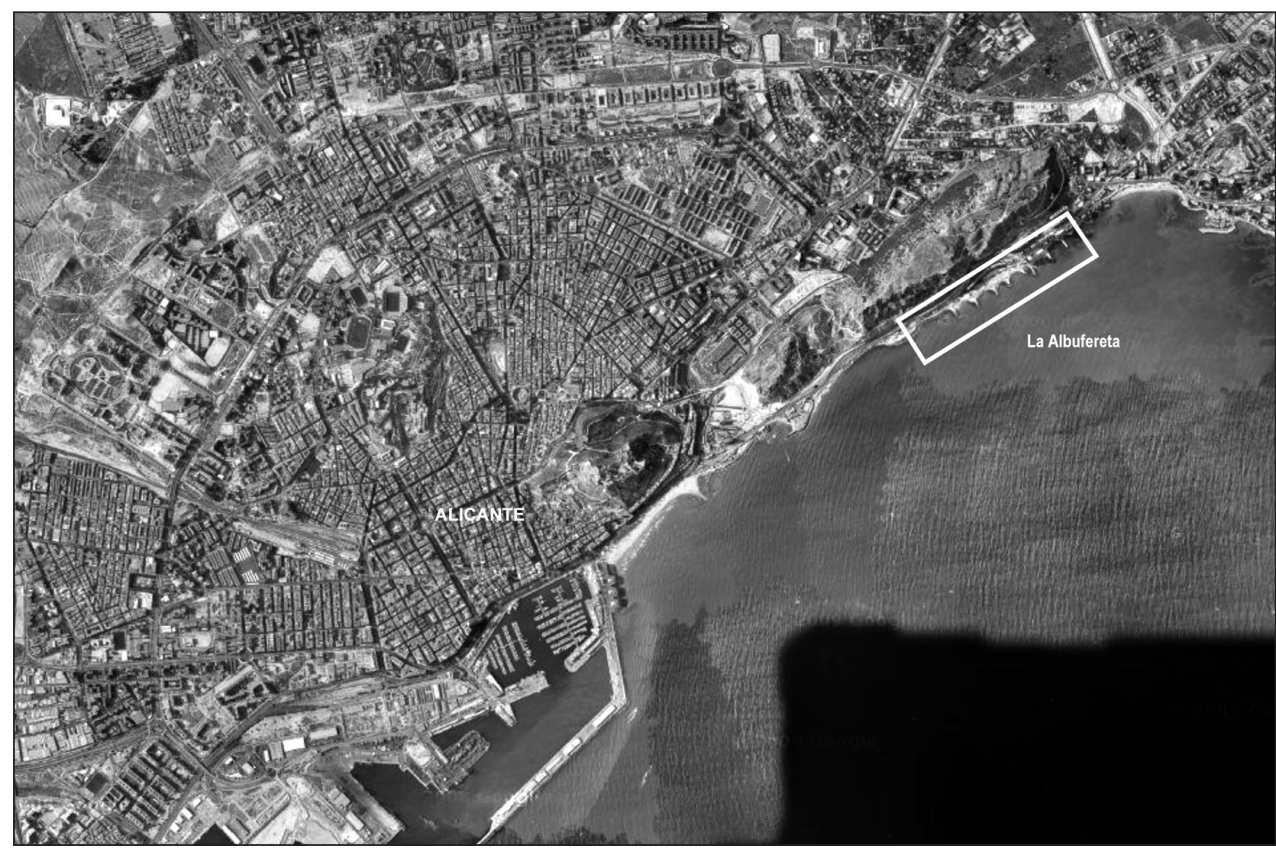

Figura 13. Imagen de la ciudad de Alicante, y del área de La Albufereta. (www.maps.google.com)

La situación en El Pinet, con ser grave y compleja, ofrece sin embargo un aspecto digno de ser tenido en cuenta: se trata de viviendas de ocupación estacional, no son viviendas principales, y en este sentido su potencial derribo no comportaría situaciones tan dramáticas como las que se vivirían en el caso de primeras residencias, ni los temporales causarían 
los mismos desperfectos que si se tratara de edificaciones en altura. Pues bien, estas dos circunstancias agravantes se dan en el caso de La Albufereta, barrio periférico residencial de la ciudad de Alicante, en el que, desde finales de los años cincuenta (la primera construcción es de 1958) se levantan grandes edificios en primera línea, sobre terrenos ganados al mar.

Las edificaciones comenzaron en 1958, sobre terrenos de difícil acceso: al pie de una cima, en una costa abrupta, casi sin espacio y muy próxima a un antiguo humedal desecado, del que deriva el topónimo. Las exigencias por parte del ayuntamiento al (un empresario llegado de Cuba, en plena guerra de la Revolución) fueron tan sólo que creara puestos de trabajo y que promoviera el desarrollo de este municipio, inmerso como los demás en la crisis estructural de la España de la autarquía (TORRES, 1997: 214).

Los inmuebles se levantaron, pues, sin ningún criterio ambiental ni de seguridad, y, por supuesto, con todas las bendiciones por parte de la Administración, que vio en estas construcciones la forma de impulsar la economía municipal. La Jefatura de Costas concede autorizaciones, amparadas en un marco jurídico muy favorable a estas actuaciones, como era la ley de Puertos de 1928. Sin embargo, desde la entrada en vigor de la ley de Costas de 1988, se inician los conflictos entre la Administración Central y las comunidades de vecinos de siete edificios ubicados en primera línea de mar, construidos en su día con todos los permisos municipales y de Costas. Al igual que sucede en el caso de El Pinet, el oleaje amenaza con dañar la estructura de los inmuebles, que en este caso no son viviendas de planta baja, sino grandes torres, una de las cuales suma 36 plantas y alcanza los 112 metros de altura.

En la actualidad, la situación todavía no se ha solucionado: queda pendiente de una sentencia del Tribunal Supremo si dos edificios (Rocafel y Helios) se encuentran -como asegura la Administración Central- dentro del dominio público marítimo-terrestre, en cuyo caso deberían pasar a ser concesiones administrativas, y los propietarios dejarían de serlo. $\mathrm{Si}$, por el contrario, se falla conforme a la petición de los vecinos, los edificios quedarían, como el resto de la zona, dentro del suelo urbano, y por tanto consolidados.

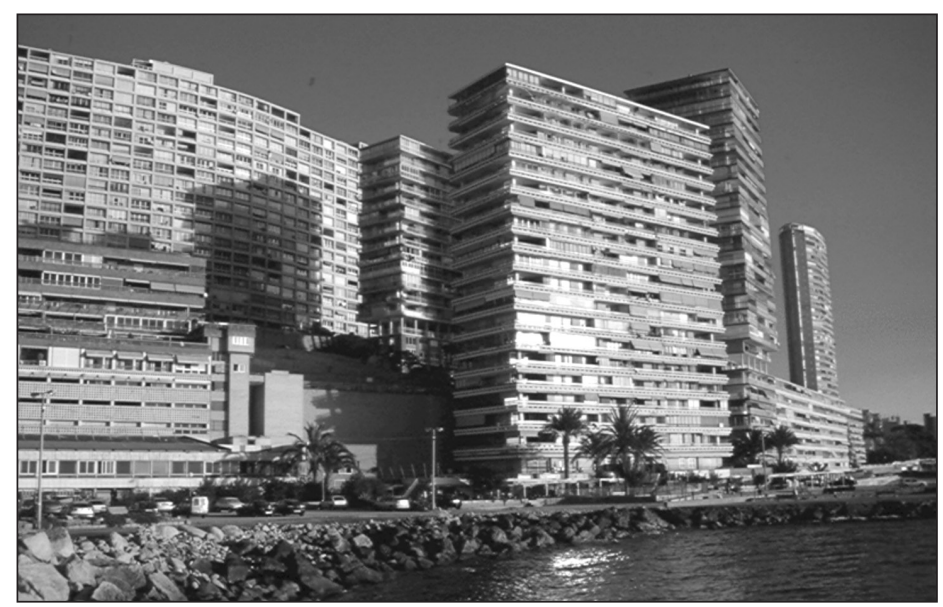

Figura 14. La Albufereta (Alicante). La mitad derecha de la imagen recoge los dos edificios de primera línea, de 20 y 26 alturas respectivamente, que según el último deslinde practicado, invaden la zona marítimo-terrestre, y cuya situación está pendiente de resolución por el Tribunal Supremo. Tras ellos, y al fondo a la derecha, edificios sobre suelo urbano, sobre cuya legalidad no existe controversia.

Foto: Francisco Torres. 
Mientras tanto, los propietarios no pueden realizar obras de defensa o reforzamiento de estructuras y balcones sin permiso de Costas (sólo muy recientemente, en 2009, el Ministerio ha consentido este tipo de reformas de manera excepcional), de manera que han estado expuestos a los embates del oleaje, teniendo que ser el Ayuntamiento el garante de la estabilidad de la escollera, y quien ha sufragado (por tanto con dinero público) la seguridad de este entorno.

\section{Estudio de caso 3. Cuando la concesión temporal deviene ocupación permanente: los puertos deportivos}

Un caso singular de concesión administrativa lo constituyen los puertos deportivos y clubes náuticos. Conviene, en primer lugar, diferenciar entre ambos: los primeros son la construcción física (dique y contradique, más la zona en tierra y el espejo de agua abrigado), aunque también se llaman puertos deportivos a las entidades de derecho privado que se sitúan en ellos, siempre que tengan finalidad lucrativa. Los clubes náuticos, sin embargo, son entidades de derecho privado, aunque sin ánimo de lucro y cuyo fin principal es el fomento de las actividades relacionadas con la náutica de recreo (escuelas de vela, competiciones, bautismos de mar...).

En cualquier caso, y sea cual sea la unidad administrativa (una o varias) que ocupen el interior de un puerto, en la práctica acaban constituyendo una ocupación permanente del dominio público marítimo-terrestre, a pesar de ostentar títulos de ocupación temporal, como son las concesiones administrativas. Para explicar esta afirmación, conviene recordar que, por tratarse de bienes de dominio público marítimo-terrestre estatal (art. 132.2 de la Constitución y art. 3 de la ley de Costas) la gestión del dominio público marítimo terrestre corresponde al Estado (art. 148 Constitución). Sin embargo, las competencias en materia de puertos (sean deportivos o de cualquier otro tipo, siempre que no se trate de puertos clasificados como de interés general), corresponde a la Comunidad Autónoma (art. 149 de la Constitución). Por tanto, el suelo debe adscribirse a la comunidad autónoma durante un periodo concreto de tiempo (generalmente 30 años), y para un uso específico como por ejemplo, uso náutico-deportivo. A través de la adscripción de suelo, la Comunidad Autónoma lo recibe de la Administración Central, y se obliga a gestionarlo subsidiariamente, de ese modo, es ella la que otorga las concesiones administrativas a los usuarios finales para -por ejemplo- ser titular de un amarre en un puerto deportivo. Sin embargo, y a diferencia de las concesiones administrativas que hemos analizado antes, y que se referían a los usos residenciales, en el caso de los portuarios una vez que caduca la concesión, el puerto no se derriba ni se desmantela (como sí sucede con una vivienda), sino que la estructura permanece y la administración saca de nuevo a concurso las concesiones. Si es preciso, se renueva la adscripción del suelo a la Comunidad Autónoma. Sólo si esto no ocurriera (no hay casos), el suelo revertiría a gestión estatal. En la práctica, por tanto, los puertos deportivos son ocupaciones permanentes del dominio público, bajo la sucesión de renovaciones constantes de los permisos temporales de ocupación.

Hay que decir que, en la renovación de la concesión, es el gobierno autonómico el que dicta las condiciones de la nueva contratación, por ser el encargado de gestionar ese suelo adscrito a la comunidad autónoma (arts. 49 y 50 LC88). De este modo, existe la posibilidad de solicitar al titular cánones de ocupación y tasas que, por su elevado coste, sólo pueden sufragar los puertos deportivos y no los clubes náuticos, que, recordemos, son entidades no lucrativas. Ésta es la situación actual, en la que se encuentran numerosos clubes náuticos de la Comunidad Valenciana, toda vez que a lo largo de esta última década ha ido venciendo la mayor parte de las concesiones, que han sido prorrogadas 
anualmente desde esa fecha. El caso del Club Náutico de Altea es bastante representativo. La sucesión de acontecimientos se detalla sumariamente:

- La concesión al Club Náutico caducó en septiembre del año 2000.

- Desde esa fecha, el gobierno regional ha prorrogado la concesión semestralmente, a la espera de sacar a concurso de nuevo la concesión administrativa, puesto que, como se ha indicado, en este tipo de instalaciones no se plantea, a diferencia de lo que ocurre con las concesiones para uso residencial, la retirada de la obra una vez expirada la concesión.

- Desde septiembre de 2006, sin embargo, las prórrogas son mensuales, y por un máximo de tres años, hasta esa misma fecha de 2009.

- El 5 de abril de 2007 se hacen públicas las condiciones que exige el gobierno autonómico (a través de la Conselleria de Infraestructuras y Transportes) para la nueva concesión. Estas condiciones se concretan en los siguientes ítems: para optar a la concesión se deberá entregar 24 millones de $\square$ para poder participar en el concurso, a modo de fianza. Deben aportarse, además, 6.000.000 $\square$ para sufragar los gatos de mantenimiento del puerto. Por último, se establece un canon anual de $400.000 \square \mathrm{a}$ la Administración autonómica.

- Las condiciones, por tanto, imponen una extraordinaria exigencia económica, imposibles de afrontar por entidades asociativas sin ánimo de lucro. No así, sin embargo, por otro tipo de empresas. La Administración autonómica entiende, pues, la gestión del suelo de soberanía nacional y uso público que es el dominio público marítimoterrestre como una forma de obtención de ingresos, y de reducción del déficit propio.

- La concesión caduca definitivamente - a la espera de posteriores prórrogas - , en septiembre de 2009. En el momento de redactar estas líneas (octubre de 2009), no se ha producido pronunciamiento alguno.

\section{Estudio de caso 4. Cuando la concesión temporal deviene ocupación permanente: restaurantes en servidumbre de tránsito}

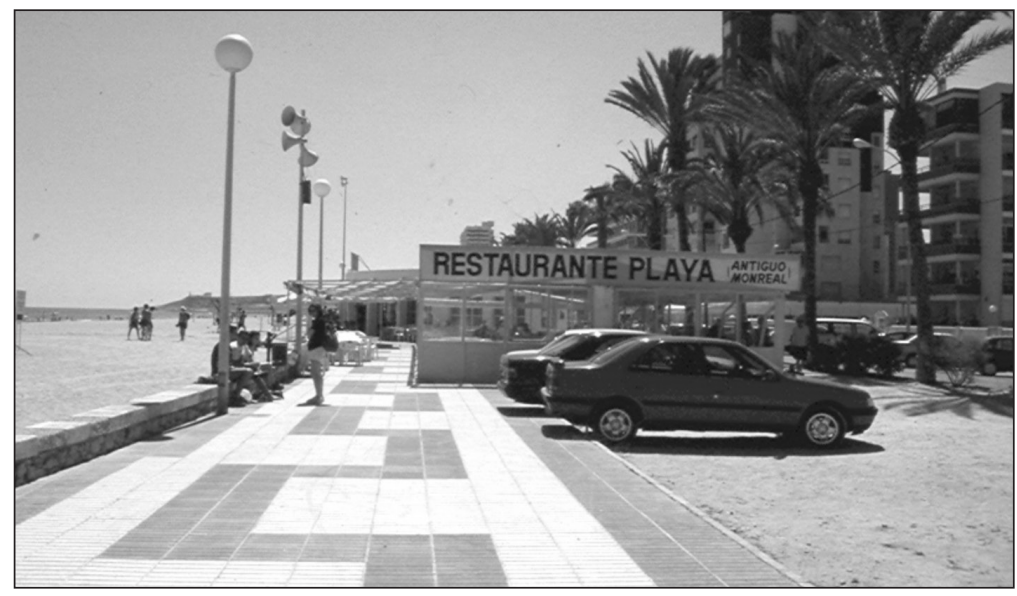

FIGURA 15. Restaurante en la servidumbre de tránsito, en régimen de concesión administrativa. Playa de San Juan (Alicante), antes de la remodelación.

Foto: Francisco Torres. 
En 1975, por tanto con el marco legal de 1969, la Administración Central concede el permiso de ocupación temporal, en régimen de concesión administrativa sobre la antigua servidumbre de vigilancia a unos particulares para la instalación de negocios de restauración. Las condiciones pactadas en el título de concesión establecen una duración de veinticinco años, motivo por el cual, el 25 de octubre del año 2000 expira el título de concesión facilitado, circunstancia, claro está, conocida por los titulares.

Y, aunque en su momento se vio lejano, el año 2000 llegó, y con él la fecha prevista para la demolición. Durante este tiempo, había entrado en vigor un nuevo texto legal, la ley de costas de 1988, que regulaba muy detalladamente las condiciones de ocupación en el dominio público y el régimen de utilización de las playa, haciendo especial hincapié en las dimensiones máximas de estas instalaciones de restauración $\left(150 \mathrm{~m}^{2}\right.$, de los cuales como máximo 100 será cubiertos) y a la distancia mínima exigible entre ellas (200 metros entre instalaciones similares $)^{6}$. A finales de octubre de 2000, por tanto, los establecimientos no sólo se encontraban fuera del periodo de concesión, sino que incumplían las condiciones establecidas en la ley de Costas, que llevaba ya en vigor doce años, y que no se había aplicado en estos casos.

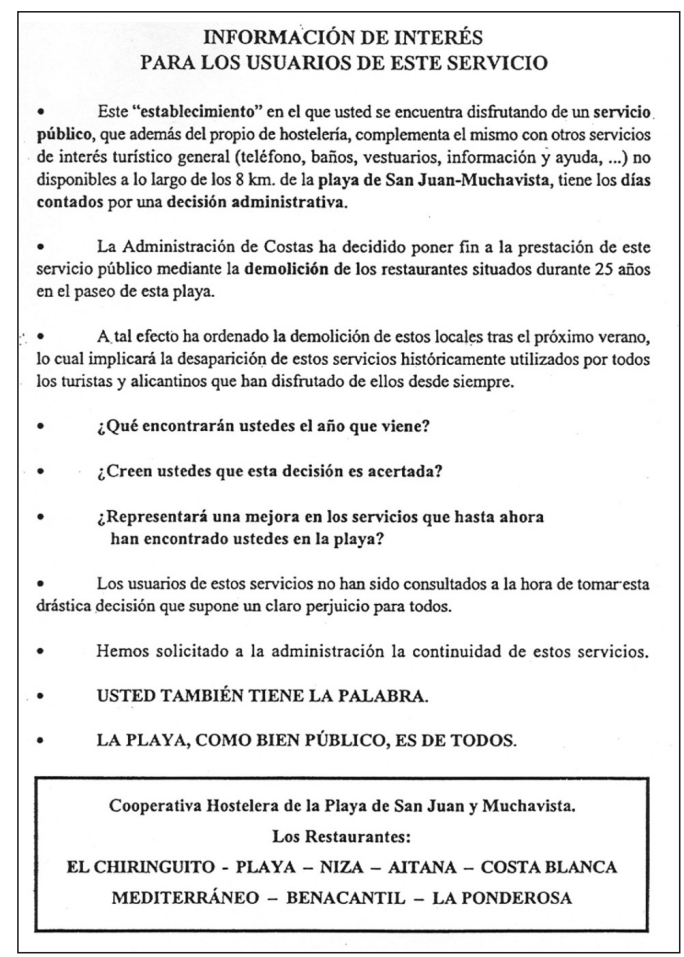

FIGURA 16. Folleto difundido por los propietarios de los establecimientos de restauración afectados por una orden de demolición en noviembre de 2002, una vez expirada la concesión administrativa de 25 años otorgada en 1975.

6 Art. 65 del Reglamento de la Ley de Costas. En él se alude también a las instalaciones desmontables, los llamados chiringuitos, para los cuales la ocupación máxima establecida es de $20 \mathrm{~m}^{2}$, con una separación mínima de 100 mts. 
La Administración Central, de acuerdo con los tribunales, fija la fecha del 14 de noviembre de 2001 para proceder a la retirada de los establecimientos. Esto supone un año más de permanencia, una vez expirada la validez del título de concesión.

Los propietarios de los establecimientos deciden agruparse en una plataforma, y recabar apoyo de la ciudadanía para evitar la demolición. Para ello difunden folletos como el de la figura 16, en el que se alude al carácter público de la playa, y al servicio que prestan para la ciudadanía como argumentos que justifican la permanencia de estas instalaciones.

Paralelamente a esta acción, que logra la recogida de 80.000 firmas de apoyo ${ }^{7}$, la plataforma de restaurantes, constituida como Cooperativa Hostelera de la playa San Juan-Mutxavista, emprende acciones legales, recurriendo la sentencia de demolición, lo que provoca que sala de lo contencioso administrativo de la Audiencia Nacional paralice la orden de derribo en tanto no se solucionen los recursos presentados. Paralelamente a este hecho, se presenta un proyecto de reforma ante el (entonces llamado) Ministerio de Medio Ambiente, de reforma de los establecimientos para adaptarlos a las nuevas condiciones establecidas en la ley de 1988, particularmente en lo que respecta a las dimensiones máximas y a la distancia entre ellos.

Sin embargo, aunque lenta, la justicia no detiene el proceso, y en febrero de 2005, una vez desestimados los recursos, la Audiencia Nacional dicta una nueva orden de derribo, el 1 de septiembre de 2005 que, no obstante, no agota la vía judicial. Los titulares de las concesiones recurren nuevamente, aunque uno de ellos, correspondiente a El Chiringuito, es desestimado y ve cómo su establecimiento es demolido puntualmente en la fecha prevista. La saturacion judicial permite a los titulares de las concesiones (extinguidas) continuar abriendo durante varios años más, hasta que, en marzo de 2008, un auto dictado por el Tibunal Supremo establece una nueva fecha para la demolición: diciembre de 2008.

Interesa destacar que la triple vía de acción (recabar apoyo popular, recurrir judicialmente y ofrecer una alternativa de adaptación, a cambio de una nueva concesión) resultó exitosa. Muy particularmente el respaldo ciudadano motivó que los consistorios municipales de los dos municipios afectados (Alicante y El Campello) se posicionaran a favor de la reclamación de los empresarios. La prensa local, por otra parte, jugó un pequeño papel no pequeño en este caso, abiertamente favorable a la presencia de estas instalaciones.

La nueva fecha implica un nuevo recurso, ya ante el Constitucional, presentado en abril de 2008, hasta que, por fin, en octubre de ese mismo año, el Gobierno paraliza la orden de demolición, pendiente desde octubre de 2001, y anuncia que los nuevos restaurantes se integrarán en el nuevo paseo marítimo. En efecto, el 30 de septiembre se alcanzaba un principio de acuerdo entre la subdelegada del Gobierno, el jefe provincial de Costas y el presidente de la Asociación Provincial de Empresarios de Hostelería de Alicante por el cual se garantizaba la presencia de establecimientos de este tipo, aunque no necesariamente bajo los mismos titulares ${ }^{8}$ (si bien algunos habían adquirido parcelas en las inmediaciones, de cara a un posible traslado si la demolición se llevaba a efecto), aunque adaptándolos a las nuevas exigencias de la ley de costas e incorporándolos en un nuevo paseo marítimo. La Administración decide, pues, sacar de nuevo a concurso la gestión de los establecimientos y anuncia, en mayo de 2009, que en octubre de ese año se derribarán los chiringuitos, considerados por los medios de comunicación como «uno de los emblemas del turismo de Alicante» ${ }^{9}$.

7 Diario Información del martes 16 de octubre de 2001.

8 Diario Información, de 1 de octubre de 2008.

9 Diario La Verdad, de 28 de mayo de 2009. 
Sin embargo, la reciente aprobación por el Parlamento Europeo del informe Auken, en marzo de 2009, titulado Impacto de la urbanización extensiva en España en los derechos individuales de los ciudadanos europeos, el medio ambiente y la aplicación del Derecho comunitario, con fundamento en determinadas peticiones recibidas, cambiará por completo la actitud de la Administración. El informe es demoledor con respecto a la aplicación de la ley del suelo, a la presencia del agente urbanizador y a la aplicación de la ley de costas en España, y motiva una Resolución del Parlamento Europeo, de 26 de marzo de 2009, por la cual, entre otras muchas exigencias, se

«4. Pide a las autoridades españolas que velen porque ningún acto administrativo que obligue a un ciudadano a ceder su propiedad privada adquirida legítimamente encuentre su fundamento jurídico en una ley adoptada después de la fecha de construcción de la citada propiedad; ello sería contrario al principio de irretroactividad de los actos administrativos, que es un principio general del Derecho comunitario (...) que garantiza a los ciudadanos seguridad jurídica, confianza y expectativas legítimas de protección en el marco del Derecho de la UE» ${ }^{10}$.

En el mismo informe, se anima a las partes perjudicadas a que, si «no obtuvieran satisfacción de los tribunales españoles, deberán recurrir ante el Tribunal Europeo de Derechos Humanos, dado que las presuntas violaciones del derecho fundamental a la propiedad no entran dentro de la competencia del Tribunal de Justicia» (art. 10), e insta a las autoridades «a que revisen urgentemente y, en su caso, modifiquen la Ley de Costas a fin de proteger los derechos de los legítimos propietarios de viviendas y de aquéllos que poseen pequeñas parcelas en zonas de la costa que no tienen un impacto negativo sobre el medio ambiente costero» (art. 22).

El impacto del informe, en el que se llega a amenazar veladamente a España con la pérdida de los fondos estructurales y de aquellos destinados a políticas de cohesión si no se atienden sus consideraciones (art. 28), es inmediato en el caso que nos ocupa: a pesar de que todas las sentencias habían sido desfavorables a la permanencia de los restaurantes, y aunque éstos llevan casi diez años más en este espacio tras haber caducado la concesión, el 30 de septiembre de 2010 el Gobierno, a través de la nueva titular del Ministerio de Medio Ambiente, anuncia la prórroga hasta 2025 de la concesión para cinco de los siete titulares de los establecimientos, aunque con un diseño homogéneo y adaptados a las dimensiones establecidas en el reglamento de la Ley de Costas.

\section{Ocupación legal por particulares: las autorizaciones}

Existen ciertos usos que, por su naturaleza, no pueden tener otra ubicación que la playa o sus inmediaciones. Particularmente aquellos relacionados con el disfrute de ésta, como las instalaciones lúdicas y muy especialmente los servicios (aunque privados) de patines, hamacas, sombrillas y similares. Para este tipo de utilizaciones, que en buena parte de los casos son de temporada, existe un título de ocupación diferente al de la concesión administrativa. Se trata de las autorizaciones administrativas.

\section{Características de las autorizaciones administrativas en dominio público}

Aunque se trata de ocupaciones del dominio público, la administración que las saca a concurso es la local. Para ello el municipio debe elaborar un Plan de Ocupación de la

10 Informe Auken, art. 4 
Playa, que remite a la Dirección General de Sostenibilidad en la Costa (del Ministerio de Medio Ambiente y Medio Rural y Marino). Dicho Plan debe recoger la cantidad de establecimientos que existirán en la playa, las zonas de sombrillas, de hamacas, etc. Si la propuesta se atiene a lo dispuesto en la ley de Costas, es decir, si respeta las distancias y superficies estipuladas, probablemente el Plan será informado favorablemente.

En ese caso, el ayuntamiento sacará a concurso público los servicios con los que contará la playa (por lo general, a través del Boletín Oficial de la Provincia; excepcionalmente se emplea el Boletín Oficial autonómico). El ayuntamiento atiende a las propuestas presentadas, y escoge aquella que considera más razonable: bien por ser la que más dinero ofrece, bien por ser la que más garantías ambientales y de servicios al usuario sugiere.

A diferencia de las concesiones, que como vimos podían aplicarse a usos residenciales (en virtud de la Transitoria Primera de la LC88), no existe la posibilidad de conceder una autorización administrativa a usos residenciales. Tan sólo se conciben para usos lucrativos.

El plazo de otorgamiento de este título suele ser breve, generalmente de una temporada; el artículo 52.4 de la ley de Costas indica que no deben exceder de un año, aunque plantea la posibilidad de excepciones. De hecho, en ocasiones, para hacer más atractiva la oferta a las empresas potencialmente interesadas, el ayuntamiento saca a concurso autorizaciones por varios años (cinco, seis... rara vez más). La ocupación del dominio público deberá ser siempre por obras desmontables (paneles, módulos...) con cimentación puntual, o sin ella. Caducada la autorización, el ayuntamiento debe repetir el proceso y sacar de nuevo a concurso los servicios en la playa.

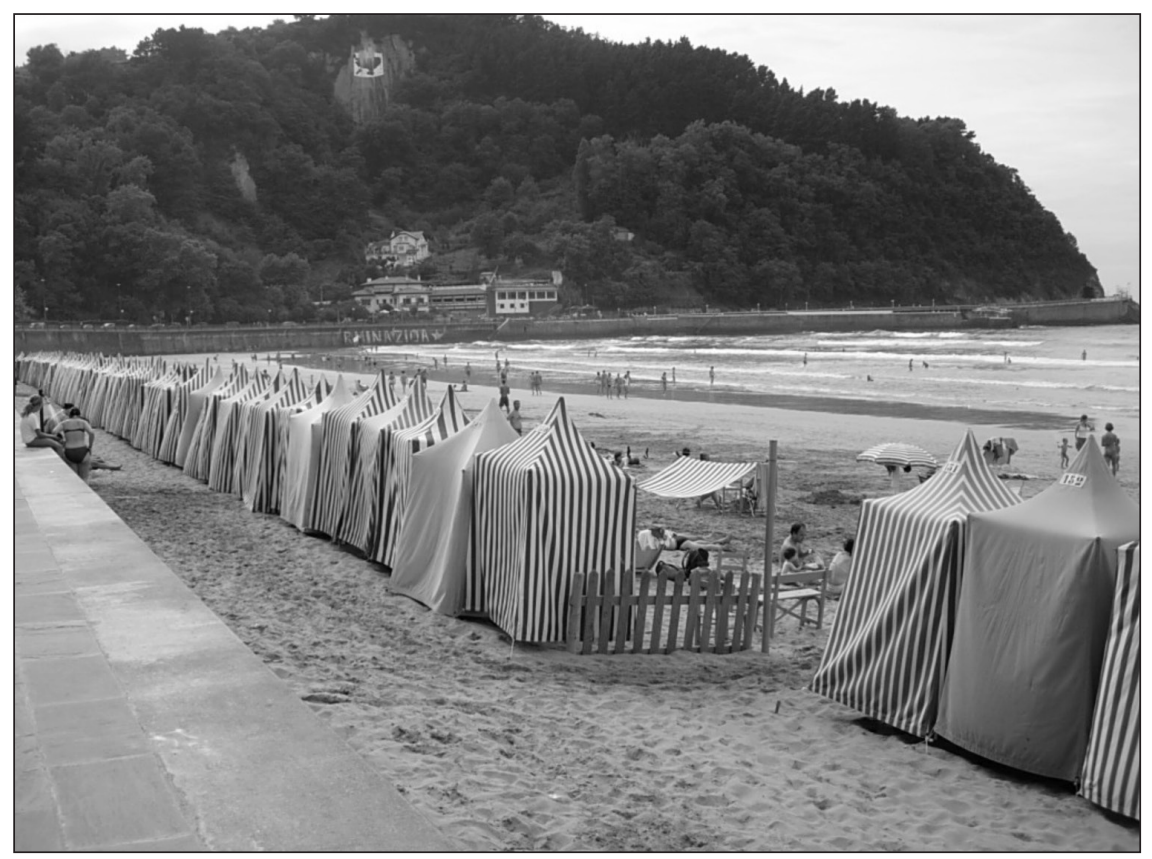

Figura 17. Casetas de baño en régimen de autorización administrativa en Zarautz (Guipúzcoa, País Vasco).

Foto: Francisco Torres. 
Varios artículos de la ley, del 51 al 54, regulan los usos posibles bajo este título de ocupación, cuyos detalles se concretan en el Reglamento de la ley de Costas. La idea es hacer compatible la conservación de la playa y sus valores naturales y ambientales, que no deben ser lesionados, con la prestación de servicios de temporada, fuertemente demandados, al tiempo que - - esto acaba siendo lo más importante - queda regulada una actividad económica de gran repercusión municipal ${ }^{11}$.

Por su carácter breve, por el hecho de que no acogen usos residenciales, y porque en ningún caso derivan de ordenamientos anteriores, las autorizaciones administrativas para ocupar el dominio público marítimo-terrestre no derivan en conflictos de tanta gravedad, duración y complejidad como los que hemos visto en el caso de las concesiones administrativas. En todo caso se pueden producir ciertas disfunciones en el procedimiento de tramitación, o reclamaciones de las empresas que no han logrado la obtención de la autorización. Rara vez estos asuntos trascienden al usuario o afectan al espacio en el que se desarrolla la actividad.

\section{Conclusión: la ocupación del dominio público y la ausencia de una verdadera política integrada del litoral}

Las ocupaciones del dominio público marítimo-terrestre generan, como hemos visto, complejos escenarios y situaciones que obligan a una gestión muy delicada de este espacio tan sensible, y de tanto interés económico, social y ambiental. Sin duda la mayor parte de estos problemas no deriva de una escasa regulación normativa, ya que, como ha quedado expuesto, la normativa española sobre costas es, aunque tardía, suficientemente amplia y detallada como para atender estas situaciones, por complejas que sean.

Sin embargo, donde probablemente sí procede actuar no es en el plano normativo, sino en el operativo. Podemos afirmar, sin temor a equivocarnos, que España carece de una verdadera política integrada del espacio litoral. De hecho, los políticos responsables de esta materia parecen mostrar una notable falta de criterio, y de una visión estable sobre este espacio, que queda así condicionado no sólo a los cambios políticos entre administraciones - podríamos pensar que los distintos colores políticos generan, aunque no siempre es así, distintas formas de actuación sobre el territorio-, sino incluso a diferentes perspectivas dentro de la misma administración.

Varias son las causas que explican, a nuestro juicio, los motivos por los cuales España carece de una verdadera política integrada del litoral. Son los siguientes:

\section{Dificultades jurídico-administrativas}

a. Derivadas de la tardía aprobación de la ley de Costas actual

Cuando, en julio de 1988, entra en vigor la Ley de Costas, buena parte del litoral mediterráneo español ofrecía un grado de urbanización elevado. La situación era tal, que el propio Reglamento de la Ley debió establecer - en las Disposiciones Transitorias 8 y 9 - excepciones a los 100 metros de la servidumbre de protección, como hemos visto. De ese modo, se consentían los usos existentes en todos aquellos sectores costeros que, el 1 de enero de 1988, estuvieran asentados sobre suelo clasificado como urbano, o urbanizable con plan parcial aprobado definitivamente. Para estos espacios, la servidumbre quedaba limitada a 20 metros, como se ha dicho, y con el añadido de obligar al respeto de las construcciones $\mathrm{y}$ actividades existentes.

11 Entre 2002 y 2007, los ingresos del Ayuntamiento de Benidorm en concepto de canon por ocupación de las playas por negocios que las ocupan bajo la forma de autorizaciones administrativas (hamacas, sombrillas, esculturas en arena...) ascendieron a 5.877.890 euros. 
Teniendo esto en cuenta, es posible hacer una primera diferenciación entre los lugares de costa en los que era aplicable la servidumbre de 20 metros (es decir, aquellos donde el frente costero estaba ya consolidado) y aquellos otros en los que la servidumbre de protección podría llegar a 100 metros, y que eran, por tanto, los suelos no urbanizables. Si trasladamos los datos provinciales a un mapa, podremos comprobar cómo cinco provincias españolas, todas ellas mediterráneas, tenían su fachada costera urbanizada en más de un $60 \%$ el 1 de enero de 1988. Se trata, por orden decreciente, de Girona (80\%), Barcelona (79\%), Málaga (66\%) Alicante (64\%) y Valencia (63'6\%) (TORRES, 1997).

Si reducimos la horquilla, encontramos que, con un porcentaje urbanizado de entre el 40 y el 60\%, debemos añadir tres provincias mediterráneas: Castellón (44’7 \%), Granada (42’77\%), Tarragona (40\%), y la isla de Gran Canaria (43’5\%).

Los datos son estremecedores, sobre todo si tenemos en cuenta que se trata de valores medios, y de base provincial. Un análisis municipal ofrece porcentajes de ocupación que superan el $90 \%$ en algunos casos, y llega al 100\% en otros, como en varios municipios de la provincia de Alicante. El resultado cartográfico es éste:

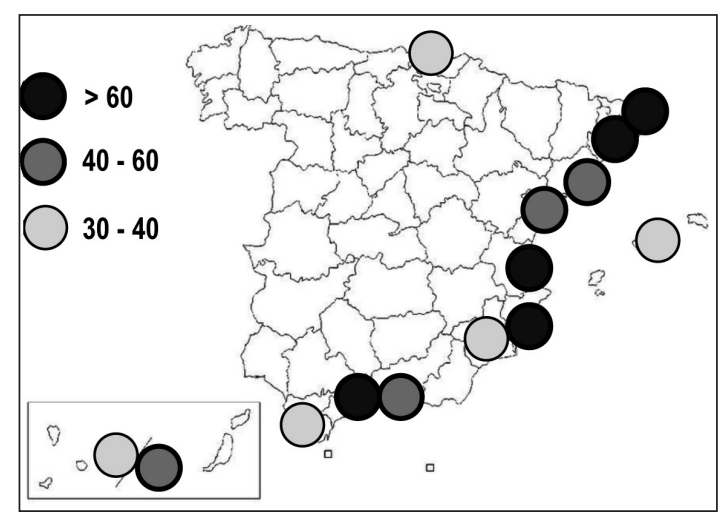

FIGURA 18. Porcentaje de costa de cada provincia en el que la servidumbre de protección es de sólo 20 metros, atendiendo a las disposiciones transitorias 8 y 9 del Reglamento de la Ley de Costas. Equivale, por tanto, al porcentaje de suelo costero clasificado como urbano o bien como urbanizable programado con plan parcial aprobado definitivamente antes del 1 de enero de 1988. Fuente: TORRES (1997).

Elaboración propia.

b. Derivadas de un deslinde incompleto e inacabado

La ordenación del litoral requiere, entre otras acciones, disponer de un deslinde actualizado, completo y fiable de todo el litoral español. A pesar de que la ley de Costas de 1969 establecía un plazo de cinco años para realizarlo, en la fecha actual (otoño de 2009), esta tarea sigue pendiente. La misma ley de Costas de 1988, consciente de esta dificultad, ya no se fijó plazo alguno, aunque recientemente se ha abordado de nuevo la tarea, a través del Plan Nacional de Deslindes (2004-2008), cuyo objetivo era culminar esta empresa en la última de las fechas. Sin embargo, dicho Plan ha transcurrido ya y los datos facilitados por el Ministerio demuestran que, a pesar del esfuerzo, aún no ha terminado esta tarea: 


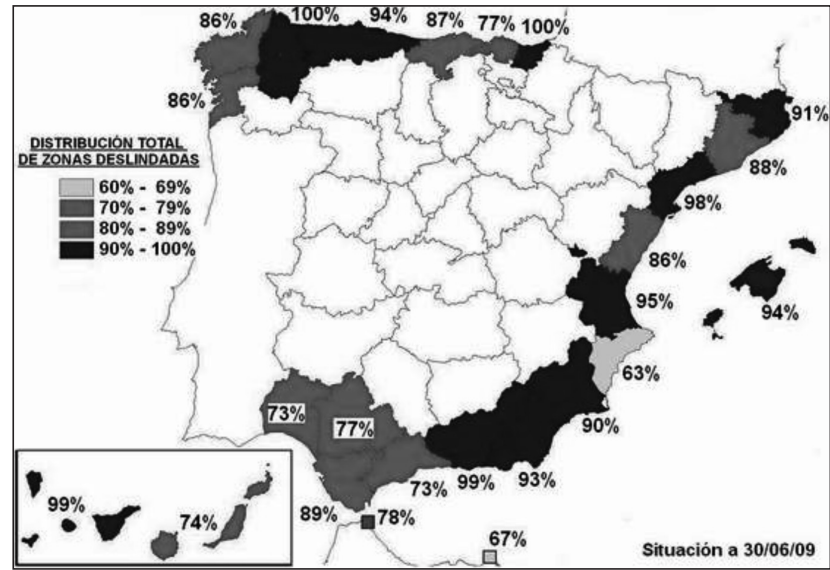

FIgura 19. Porcentaje de costa deslindado.

Fuente: Ministerio de Medio Ambiente y Medio Rural y Marino.

Fuente: http://www.mma.es/portal/secciones/aguas_marinas_litoral/gdpmt/deslinde.htm

La provincia de Alicante, por ejemplo, aún tiene pendiente de deslindar el $37 \%$ de su frente costero. Es el caso más desfavorable. Otras provincias intensamente urbanizadas, como Málaga, tiene deslindado un $73 \%$, la misma cifra que Huelva, ya en la costa atlántica. En general, el Cantábrico tiene porcentajes de deslinde mayores, lo que se explica por una menor urbanización, que redunda a su vez en una menor complejidad técnica y sobre todo jurídica para establecer el alcance del dominio público. No debemos olvidar que al acto de deslinde suelen suceder los recursos por la vía administrativa de los particulares cuyas propiedades se ven afectadas, y en este sentido puede comprenderse la menor velocidad de actuación en aquellos espacios más densamente ocupados.

\section{Dificultades económicas}

Desafortunadamente, una verdadera política de recuperación de espacios costeros para uso público, requiere no sólo la voluntad de los políticos y el respaldo de los agentes sociales (empresas, sindicatos, ciudadanía en general), sino, y sobre todo, de una financiación estable y segura. Los presupuestos asignados a la Dirección General de Costas (hoy llamada de Sostenibilidad en la Costa), aunque han experimentado un incremento notable en los últimos diez años, siguen siendo exiguos, y claramente insuficientes para afrontar indemnizaciones, justiprecios y compras de terrenos por parte del Estado, como se hace en el Reino Unido a través del National Trust, o en Francia mediante el Conservatoire du Littoral ${ }^{12}$.

Algunos datos nos servirán para demostrar que, en este momento, las políticas de conservación y ordenación del litoral no son una prioridad ni dentro del Ministerio de Medio Ambiente, Rural y Marino (MARM), ni dentro de la estructura ministerial en general:

Presupuesto de la Dirección General de Costas (2008) $291 \mathrm{M} \square$

Presupuesto del MARM (2008) $4.289 \mathrm{M}$

12 El Programa de Adquisición de Fincas, de la D.G. de Sostenibilidad en la Costa no alcanza, ni en los medios ni en los objetivos, las dimensiones ni los resultados de los modelos británico y francés citados. 
Por tanto, las políticas litorales suponen el 6’78\% del total del Ministerio. Por el contrario, las políticas relacionadas con el agua (tema estrella de la legislatura anterior), ascienden al $64 \%$ del total de ese mismo Ministerio (desalación, reutilización, calidad del agua, etc.). La comparación con otros gastos e inversiones presupuestarias deja en evidencia la parquedad de las arcas destinadas a la conservación del litoral: por ejemplo, para 2009 el presupuesto asignado a la Dirección General de Correos, adscrita al Ministerio de Fomento, fue de $2.645^{\prime} 3$ millones de euros ${ }^{13}$, es decir, nueve veces más que lo asignado a Costas ese mismo año (casi 291 millones de euros). El ministerio de Fomento, en fin, tiene presupuestado para 2009 un total de 30.759'7 millones de euros (de los que más de 13.800 se destinan a ferrocarriles, especialmente por las líneas de alta velocidad), lo que supone casi 50 veces más que el presupuesto de Costas. Y, por último, el presupuesto de la Universidad de Alicante para 2009 es de 200'79 millones de euros ${ }^{14}$, lo que supone el $69 \%$ del total presupuestado para la Dirección General de Sostenibilidad en la Costa para ese año. Con el perímetro costero a falta de un deslinde completo, y buena parte de los recursos planteados por los propietarios/concesionarios pendientes de resolver, sólo puede concluirse una auténtica falta de voluntad política que está, claro, detrás de esta escasez presupuestaria.

\section{Dificultades políticas derivadas de la aritmética parlamentaria}

Un aspecto habitualmente poco valorado, pero que resulta de extraordinaria trascendencia: la voluntad política debe contar con el suficiente respaldo en el Parlamento, con el fin de que determinados temas «de estado» (educación, sanidad, ordenación del territorio, y por supuesto del litoral), no estén sometidos a las exigencias puntuales de grupos minoritarios. En España, tras las últimas elecciones generales, que tuvieron lugar en marzo de 2008, el resultado no ofrece seguridad al partido mayoritario para sacar adelante políticas que afectan a las comunidades autónomas, como es la ordenación del territorio y del litoral:

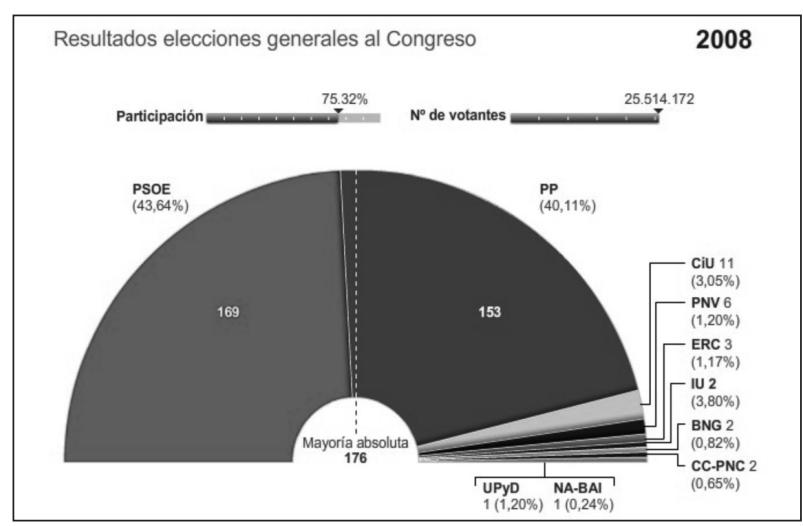

Figura 20. Composición del Parlamento Español tras las elecciones generales del 9 de marzo de 2008.

Fuente: http://www.elpais.com/graficos/espana/Resultados/elecciones/generales/2008/elpgranac /20080309elpepunac_2/Ges/

13 http://www.ief.es/documentos/recursos/publicaciones/revistas/presu_gasto_publico/54_10.pdf

14 http://www.docv.gva.es/portal/portal/2009/02/26/pdf/2009_1992.pdf 
Con estos datos, y puesto que la composición total es de 350 escaños, la mayoría absoluta se sitúa en 176. El partido mayoritario necesita, para cualquier votación en el Parlamento, el apoyo de siete diputados de otros partidos políticos, es decir - excluyendo el apoyo improbable del principal partido de la oposición-, o de los nacionalistas catalanes (único grupo que tiene al menos esos siete escaños), o de como mínimo dos grupos parlamentarios. Dado que la composición del Parlamento es muy heterogénea, y la mayor parte de los grupos son de carácter regionalista, nacionalista e incluso independentista (de hecho sólo cuatro partidos son de ámbito nacional: los dos mayoritarios, más I.U. y UpyD) es fácil comprender que el partido en el gobierno debe atender a las sensibilidades periféricas a la hora de afrontar las diferentes políticas de Estado. La misma aprobación de los Presupuestos Generales del Estado está pendiente de los apoyos parlamentarios, que se producen siempre condicionados a la obtención de mejoras fiscales y/o estatutarias. En esta situación, es fácil intuir que una verdadera política integrada, de carácter nacional, resulta empresa complicada, aunque es preciso reconocer que incluso cuando se ha contado con mayorías absolutas, la falta de interés decidido por afrontar estas tareas (culminar el deslinde, rescatar terrenos privatizados de hecho, rescatar concesiones o emprender actuaciones de ordenación integrada tras su retirada...) ha sido, también, la norma habitual.

\section{Bibliografía}

Informe Auken (2009): Impacto de la urbanización extensiva en España en los derechos individuales de los ciudadanos europeos, el medio ambiente y la aplicación del Derecho comunitario, con fundamento en determinadas peticiones recibidas. Disponible en la dirección: http://www.europarl.europa.eu/sides/getDoc.do?pubRef=-//EP// TEXT+REPORT+A6-2009-0082+0+DOC+XML+V0//ES

Ley 22/1988, de 28 de julio, de Costas.

TORRES ALFOSEA, F. J. (1997): Ordenación del litoral en la Costa Blanca. Servicio de Publicaciones de la Universidad de Alicante. Alicante, 269 p.

Real Decereto 1471/1989, de 1 de diciembre, por el que se aprueba el Reglamento General para desarrollo y ejecución de la Ley de Costas. 
